\title{
NMDA-Receptor Antagonists Disrupt the Formation of the Auditory Space Map in the Mammalian Superior Colliculus
}

\author{
Jan W. H. Schnupp, Andrew J. King, Adam L. Smith, and lan D. Thompson \\ University Laboratory of Physiology, Oxford OX1 3PT, United Kingdom
}

In the ferret (Mustela putorius) the map of auditory space in the deeper layers of the superior colliculus (SC) matures over a period of several postnatal weeks, a process known to be guided by both visual and auditory experience. The auditory responses are initially very broadly tuned, and gradually become more selective for specific sound locations that coincide with the visual receptive fields recorded in the same region of the SC. To investigate the possible involvement of NMDA-type glutamate receptors in the postnatal development of this auditory representation, we have reared ferrets in which $400 \mu \mathrm{m}$ thick sheets of the slowrelease polymer Elvax, containing the NMDA receptor antagonists MK801 or APV, were placed on the dorsal surface of the SC. The Elvax was implanted on postnatal day (P) 25-27, just before the onset of hearing, and removed 5-6 weeks later, just prior to recording from the $\mathrm{SC}$ on around P61-70. In vitro measurements with Elvax containing ${ }^{3} \mathrm{H}$ MK801 revealed that the amount of drug released declined sharply over the first $10 \mathrm{~d}$ and then stabilized at a fairly constant rate for the following 5 weeks. These in vitro data were found to parallel the in vivo release of MK801 from implanted Elvax slices. Diffusion of MK801 from the implant was measured and significant levels were found within $800 \mu \mathrm{m}$ of the SC surface, suggesting that the action of MK801 was restricted to the superficial and intermediate layers of the nucleus.

Extracellular recordings were made from visual and auditory units in the $\mathrm{SC}$ in response to free-field stimulation. The visual responses of units recorded in the superficial layers appeared to be unaffected by either of the drug treatments, and formed a normal, adult-like map of visual azimuth along the rostrocaudal axis of the SC in all animals. Most of the auditory single-unit responses recorded at this age in normal, unoperated controls were spatially tuned and topographically organized, although the map of sound azimuth was less precise than that in adult ferrets. Data from age-matched control animals that had been reared

\footnotetext{
Received Feb. 22, 1994; revised July 14, 1994; accepted Aug. 22, 1994.

We thank Pat Cordery for technical assistance, Du Pont (UK) Ltd. for the gift of Elvax 40P, Dr. L. L. Iversen of Merck Sharp and Dohme Research Laboratories (Harlow, UK) for the gift of MK801, Peter Kind and Richard Wingate for discussion, and David Moore for reading the manuscript. We are grateful to the Wellcome Irust (Grants U31316/L/YO/L, 039456/L/Y3/L, and $034242 / Z / 91 / Z$ ), Medical Research Council and McDonnell-Pew Centre for Cognitive Neuroscience for support. J.W.H.S. is a Wellcome Prize Student, A.J.K. is a Wellcome Senior Research Fellow, and A.L.S. is a Wellcome Vision Research Training Fellow.

Correspondence should be addressed to Dr. Andrew J. King, University Laboratory of Physiology, Parks Road, Oxford OX1 3PT, UK.

Copyright (C) 1995 Society for Neuroscience $0270-6474 / 95 / 151516-16 \$ 05.00 / 0$
}

with drug-free Elvax implants were not statistically different from the unoperated juvenile ferrets. However, in animals reared with APV or MK801 Elvax implants, there was an increase in the relative numbers of auditory units that were ambiguously tuned to two or more locations. In the MK801 group, the proportion of units tuned to a single location in space was significantly reduced compared to either of the juvenile control groups. The topography of the auditory representation was also severely impaired in animals treated with either MK801 or APV during this period of development, resulting in a much poorer alignment with the visual representation.

Adult animals that had received MK801 Elvax implants for the same duration, but beginning at P108-115, also showed a significant reduction in the proportion of tuned auditory units compared to age-matched, drug-free controls. However, in contrast to the juvenile ferrets, the topographic variation in azimuthal selectivity within the SC appeared to be unaffected by NMDA-receptor blockade in the adult animals.

These data suggest that NMDA receptors play a critical role in the activity-dependent process by which a map of auditory space in the $\mathrm{SC}$ is elaborated during development.

[Key words: NMDA, MK801, aminophosphonopentanoic acid, Elvax, superior colliculus, visual space map, auditory space map, developmental plasticity]

Neural maps of visual space and of the body surface arise as a result of topographic projections from the receptor surfaces. In contrast to these projectional space maps, a map of auditory space is a computational representation, based on the analysis of highly complex cues that derive from the acoustical properties of the head and ears. The neural circuitry involved in constructing the auditory representation relies on early sensory experience to develop normally (see reviews by King, 1993; King and Carlile, 1994). The superior colliculus (SC) is a particularly useful structure in which to study the development of topographic sensory representations, because it contains both projectional maps of the visual field and body surface and a map of auditory space (King, 1993; Stein and Meredith, 1993). Moreover, these sensory representations are topographically aligned. In ferrets, the auditory space map matures during the second and third postnatal months (King and Carlile, 1991, 1994), when surgical, pharmacological or sensory manipulations can easily be carried out. The auditory representation therefore provides a useful system for studying activity-dependent mechanisms of brain development.

The development of the auditory space map in the SC is influenced by both auditory and visual stimulation. Deprivation or 
reorganization of the visual input, by eyelid suture, dark rearing, or eye rotation, disrupts the formation of the auditory map to varying degrees (King et al., 1988; Withington-Wray et al., 1990a; Knudsen et al., 1991; King and Carlile, 1993), while small, systematic shifts of the visual field, brought about either by prisms (Knudsen and Brainard, 1991) or by a surgically induced strabismus (King et al., 1988), cause the auditory map to shift by the same amount and in the same direction, so that it remains in register with the visual map. These findings have led to the notion that visual signals may guide the development of the auditory spatial tuning of units found in the deeper layers of the SC, and, by implication, their selectivity for particular Iocalization cue values.

The mechanisms that lead to the matching of auditory cues and visual signals in the $\mathrm{SC}$ are not known. One possibility is the involvement of a Hebbian mechanism incorporating NMDAtype glutamatergic synapses (Knudsen, 1991). These receptors have been implicated in the development of different sensory systems, possibly as a means of detecting temporal correlations among simultaneously active synaptic inputs (Constantine-Paton et al., 1990; Rauschecker, 1991; Fox and Daw, 1993). Of particular relevance to the present investigation is the finding that NMDA receptors are involved in the experience-dependent matching of binocular visual maps in the optic tectum of developing Xenopus frogs (Scherer and Udin, 1989). In a similar fashion, NMDA receptors may provide a means of selectively enhancing synaptic inputs that encode the auditory spatial cues for the location also signaled by visual inputs arising from the same himodal stimulus.

Most of the evidence implicating NMDA receptors in sensory development has come from studies showing that blockade of these receptors affects the plastic rearrangement of maps in response to altered sensory inputs. In this study, we show that chronic application of NMDA-receptor antagonists disrupts the normal development of the auditory map in the SC, which lends support to the notion that a mechanism of coincidence detection and Hebbian modification of the neural circuitry are involved in the generation of the computational map of auditory space in this nucleus.

Preliminary results have been published in abstract form (Schnupp et al., 1993a,b).

\section{Materials and Methods}

Preparation of the Elvax implants. Elvax 40P was a gift from Du Pont (UK) Ltd. (+)-10,11-Dihydro-5-methyl-5H-dibenzo(a,d)-cyclohepten5,10-imine maleate (MK801) was a gift from Dr. L.L. Iversen, Merck Sharp and Dohme Research Laboratories, Harlow, UK. (+)-3- ${ }^{3} \mathrm{H}-$ MK801 (25.7 Ci/mmol) was obtained from New England Nuclear (Boston, MA). $\mathrm{D}(-)$-2-Amino-5-phosphono-4,5-3 $\mathrm{H}$ pentanoic acid $\left({ }^{3} \mathrm{H}\right.$ D-APV) $(25 \mathrm{Ci} / \mathrm{mmol})$ and D-APV were purchased from Tocris Neuramin (Langford, UK). Fast green FCF was supplied by Allied Chemical (Morristown, NJ) and all other chemicals were obtained from Sigma (Poole, UK).

MK801-impregnated Elvax. Pellets of Elvax 40P (1 gm) were dissolved in dichloromethane to give a $10 \%$ (w/v) solution. To the Elvax solution was added the required amount of MK801 dissolved in dimethyl sulfoxide (DMSO) $(200 \mu \mathrm{l})$ giving a final concentration of either $1 \mathrm{mM}$ or $10 \mathrm{~mm} ; 1 \%$ fast green in DMSO $(100 \mu \mathrm{l})$ was then added to help visualize the Elvax slices. The solution was agitated on a vortex mixer for $10 \mathrm{~min}$ and then poured without delay into a glass mould embedded in $\mathrm{CO}_{2(s)}$. After leaving the Elvax solution to freeze for 10 min the mould was transferred to a freezer at $-70^{\circ} \mathrm{C}$. After a further hour the mould was removed and the frozen block was left at $-70^{\circ} \mathrm{C}$ for $2 \mathrm{~d}$. In order to remove the solvent from the Elvax the block was then desiccated in a freeze-dryer for $2 \mathrm{~d}$, over which period considerable shrinkage occurred. The dry Elvax block was then sectioned at the desired thickness on a freezing microtome prior to implantation. All Elvax slices were washed in sterile phosphate-buffered saline (PBS) for $3 \mathrm{~d}$ at $37^{\circ} \mathrm{C}$ before use to eliminate the high concentrations of drug that were released from the slices on initial rehydration (see below).

D-APV-impregnated Elvax. The required amount of D-APV was dissolved in the minimum volume of water $(20-50 \mu \mathrm{l})$ and this solution was added to a solution of Elvax 40P in dichloromethane $(10 \%, 10 \mathrm{ml})$, prepared as described above. A solution of fast green FCF in water $(5 \%, 20 \mu \mathrm{l})$ was added to give a final concentration of $0.01 \%$ fast green. The suspension of aqueous solutions in dichloromethane was then agitated on a vortex mixer for $10 \mathrm{~min}$ to give suspensions with a final concentration of either $1 \mathrm{mM}$ or $5 \mathrm{mM}$ D-APV. The vortexed suspension was immediately poured into a mould for freezing and the Elvax block treated as described for MK801-impregnated Elvax.

Implantation of Elvax. Under Saffan anesthesia (Alphaxalone/Alphadolone acetate; $2 \mathrm{ml} / \mathrm{kg}$ ), $400 \mu \mathrm{m}$ thick sheets of Elvax were placed, usually bilaterally, onto the dorsal surface of the SC in 16 ferrets at P25-27, which is just before the onset of hearing (Morey and Carlile, 1990). The eyes were still closed in all cases. These animals received Elvax loaded with $10 \mathrm{mM}$ MK801 (number of ferrets, $N=4$ ), $1 \mathrm{mM}$ MK801 $(N=3), 5 \mathrm{mM}$ APV $(N=3)$, or DMSO as a drug-free control $(N=6)$. A craniotomy was made over the SC and the occipital cortex aspirated to reveal the midbrain. The Elvax was carefully placed to cover the SC as completely as possible without impinging on the inferior colliculus. The cavity was filled with absorbable gelatin sponge (Sterispon, Allen and Hanbury, London) and the bone flap replaced. After suturing the scalp, the animal was injected with antibiotic (Penbritic, Beecham, Brentford, UK; $0.1 \mathrm{ml}$, i.m.).

The animals were recovered and allowed to develop normally until they were aged P61-70 (mean $\pm \mathrm{SD}=39 \pm 3 \mathrm{~d}$ after implantation). This time period was chosen as previous multiunit recordings had shown that much of the formation of the auditory space map takes place during the 2nd postnatal month (King and Carlile, 1991, 1994). Three normal ferrets aged P63-64 were also used to provide age-matched, unoperated controls. In addition, recordings were made from three adult ferrets aged $\mathrm{P} 136-158$ that had previously received Elvax implants containing $10 \mathrm{~mm}$ MK801 on P108-115 (mean $\pm \mathrm{SD}=37 \pm 7 \mathrm{~d}$ duration of treatment), as well as three adult control animals aged P161-169 that had been implanted with drug-free Elvax slices on P131 (mean \pm SD $=34 \pm 4 \mathrm{~d}$ after implantation). On the day of recording, the animals were reanesthetized with an intraperitoneal injection of a mixture of medetomidine hydrochloride (Domitor) and ketamine (Vetalar) at a dose of $250 \mu \mathrm{g} / \mathrm{kg}$ and $60 \mathrm{mg} / \mathrm{kg}$, respectively, and then provided with a continuous intravenous infusion of Domitor/ketamine mixture $(42 \mu \mathrm{g}$ and $10 \mathrm{mg} / \mathrm{kg} / \mathrm{hr}$ ) in Locke solution. They also received an initial dose of $0.06 \mathrm{mg}$ atropine sulfate intraperitoneally and $3 \mathrm{mg}$ doxrapam (Dopram-V) intramuscularly. The administration of atropine and Dopram was repeated at 12 hourly intervals during the course of the experiment. The trachea was cannulated, so that the airways could be cleared at regular intervals. Body temperature was monitored with a rectal probe, and held constant at $39^{\circ} \mathrm{C}$ with an electric blanket. The craniotomy, which by this time had completely healed in all animals, was reopened and the position of the Elvax was inspected after further aspiration of the overlying cortex. The experiment was continued only if the Elvax was found to cover the whole of the SC on at least one side. Three of the juvenile animals reared with drug-free Elvax had to be abandoned because the Elvax had moved away from the SC. Electrophysiological data were therefore obtained from seven juvenile ferrets reared with MK801-Elvax implants (four ferrets with $10 \mathrm{mM}$ MK801 and three with $1 \mathrm{mM}$ MK801) plus three animals in each of the other groups. Recordings were made unilaterally within an hour of removing the Elvax. For comparison, data are also included from 38 normal, adult ferrets that had been used in previous studies (see King and Hutchings, 1987; King and Carlile, 1993; Carlile and King, 1994; King et al., 1994).

In order to estimate the extent and time course of the release of MK801 and D-APV from the Elvax slices, a small fraction of radiolabeled MK801 or D-APV was incorporated in the Elvax. The dilution factor of the ${ }^{3} \mathrm{H}-\mathrm{MK} 801$ was $1: 50,000$ while that of the $\mathrm{D}-{ }^{3} \mathrm{H}-\mathrm{APV}$ was $1: 10,000$. Slices of Elvax $(400 \mu \mathrm{m})$ were incubated in PBS $(0.5 \mathrm{ml})$ at $37^{\circ} \mathrm{C}$ and the bathing solution changed every $48 \mathrm{hr}$. The amount of radioactivity released during this period was measured by scintillation counting, so that, by appropriate scaling, the total amount of drug released from a slice $\left(\mathrm{pmol} / \mathrm{mm}^{2}\right)$ could he calculated. The data obtained from slices under these conditions were compared with the in vivo re- 

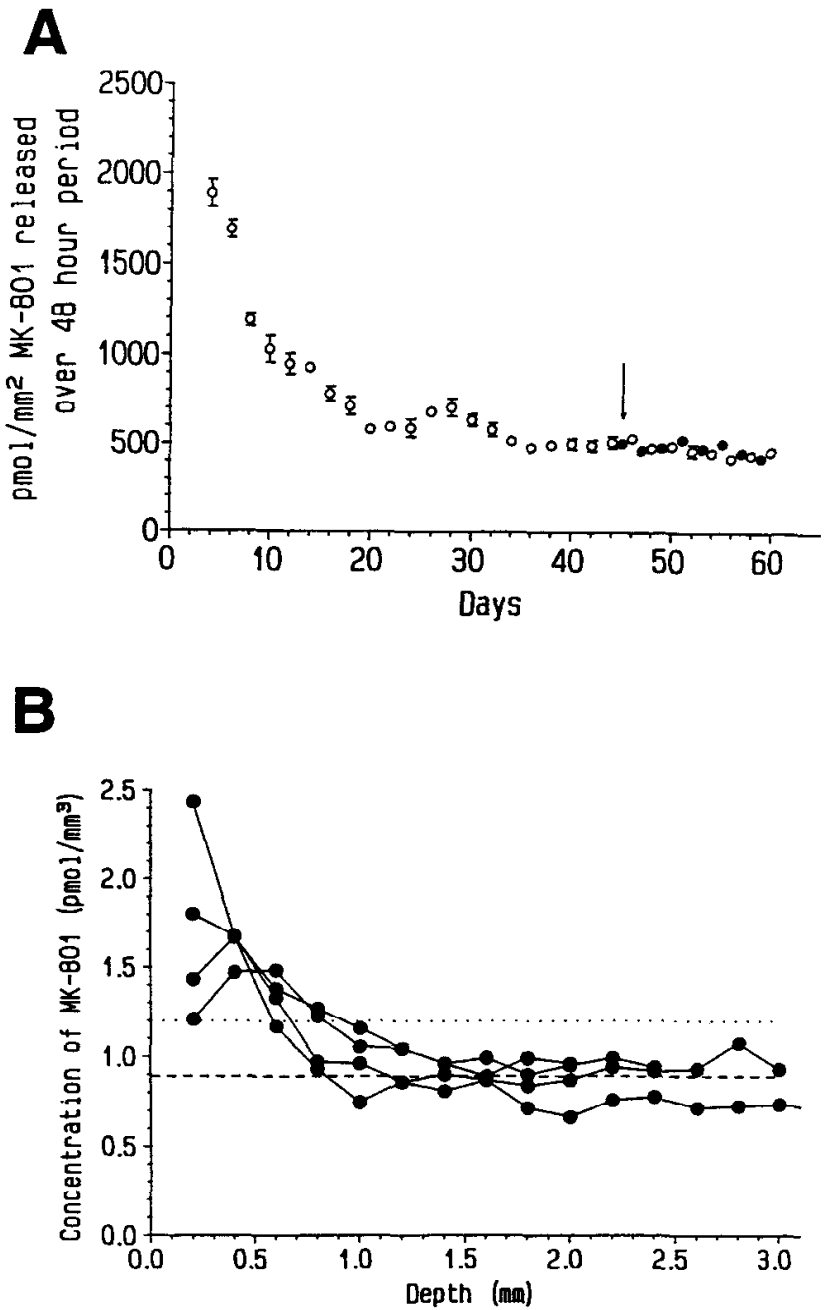

Figure 1. Elvax release characteristics. $A$, The total release of MK801 over $48 \mathrm{hr}$ intervals in $\mathrm{pmol} / \mathrm{mm}^{2}$ from four $400 \mu \mathrm{m}$ thick slices of Elvax containing $10 \mathrm{mM} \mathrm{MK} 801$, which were incubated in PBS at $37^{\circ} \mathrm{C}$ for the entire $60 \mathrm{~d}$ period (open circles) and from a single slice that was implanted over the ferret superior colliculus for $43 \mathrm{~d}$ before being incubated in PBS at $37^{\circ} \mathrm{C}$ (solid circles; onset of in vitro release measurements indicated by arrow). The in vitro measurements are the arith metic mean of four determinations and the error bars indicate the SE $B$, The concentration of MK801 below $10 \mathrm{mM}$ MK801 Elvax implants as a function of depth within the superior colliculus. Data for four nuclei are shown, together with the mean background level of MK801 (dashed line), measured in brain sections distant from the Elvax implant. The dotted line indicates two SDs from the mean background level, which was significantly greater than the background level in the brain of animals that had not received an Elvax implant $(p<0.05)$.

lease characteristics of implanted slices by monitoring the amount of drug released after the slices were removed from the animals.

The release characteristics of slices embedded in the brain and those incubated at $37^{\circ} \mathrm{C}$ were found $t o$ be very similar. In both cases, release from MK801-containing slices continued for over $60 \mathrm{~d}$. Although the level of release was dependent upon the concentration of the MK801, both $1 \mathrm{~mm}$ and $10 \mathrm{~mm}$ preparations gave sustained levels of drug delivery throughout the entire period. In the case of D-APV-containing slices, however, an extremely rapid fall in release rate was observed. This was presumably due to the high aqueous solubility of D-APV and resulted in the predominant use of MK801-containing slices for the electrophysiological experiments.

The close correlation between release from slices in vivo and in vitro is illustrated in Figure $1 A$ in which the in vitro release curve for 400 $\mu \mathrm{m}$ slices of $10 \mathrm{~mm}$ MK801 Elvax is compared with that of an identical slice that had been implanted over the SC for $43 \mathrm{~d}$. The almost exact match of the data from days $45-60$ indicates that, as predicted from in vitro measurements, the release of MK801 from the implanted slice was continuous throughout the period of implantation and had also fallen to a constant level by this stage.

A further two juvenile ferrets were implanted with $10 \mathrm{mM}{ }^{3} \mathrm{H}-\mathrm{MK} 80$ I Elvax slices in order to measure the diffusion of MK801 into the SC. The animals were sacrificed $7 \mathrm{~d}$ after Elvax implantation. The superior colliculi were rapidly frozen and cryostat-sectioned at $200 \mu \mathrm{m}$ intervals parallel to the plane of the Elvax slice. The amount of ${ }^{3} \mathrm{H}-\mathrm{MK} 801$ in a known tissue volume was then determined by scintillation counting and the concentration of MK801 calculated by appropriate scaling. Figure $1 B$ shows the concentration of MK801 measured in four superior colliculi as a function of depth. The concentration of MK801 within the first $800 \mu \mathrm{m}$ below the Elvax implant was found to be significantly greater than that in other brain areas $(p<0.02)$

Preparation for recording. Care was taken to reconstruct the natural position of the outer ears after the craniotomy, so that filtering of the auditory stimuli by the outer ear would be normal. The eyelids contralateral to the $\mathrm{SC}$ from which the recordings were to be made were removed. The animals were not paralysed, so eye movements were minimized by running sutures through the conjunctiva and fixing them to the skin surrounding the eye with tissue adhesive (Vetbond, SM Animal Care Products, St. Paul, MN). A zero refractive power contact lens was then placed on the eye. The exposed SC was covered with a thin layer of $2 \%$ agar dissolved in physiological saline to stabilize it against pulsations caused by the animal's breathing and heartbeat, and to prevent it from drying out. The animal was then transferred to an anechoic chamber and placed on a small table at the center of a robotic hoop of $65 \mathrm{~cm}$ radius (Annetts et al., 1987), which was used to present auditory or visual stimuli from any desired direction with respect to the animal's head. A bright, flashing LED (1 $\mathrm{cm}$ in diameter) was used as a visual stimulus. The auditory stimulus consisted of a flat, broadband (20$30,000 \mathrm{~Hz}$ ) digitally generated noise pulse (Carlile and Hollingshead, 1991) of 100 msec duration.

Neural activity was recorded with a tungsten microelectrode with a typical tip length of about $20 \mu \mathrm{m}$. The signal was bandpass filtered $(500-5000 \mathrm{~Hz})$ and amplified between 5000 and 10,000 times, depending on the strength of the signal. The amplified signal was fed into an auditory monitor, a digital storage oscilloscope and an A/D converter (Cambridge Electronic Design 1401plus laboratory interface, Cambridge, UK) for spike shape analysis (see below).

Mapping visual responses in the superficial layers. The electrode was lowered into the $\mathrm{SC}$ using a remotely controlled motorized microdrive. Once the electrode had entered the SC, as indicated by strong responses to the visual stimulus placed in front of the eye, the receptive fields of superficial-layer units were mapped using the hoop-mounted LED with the aid of an audio monitor and an oscilloscope. The locations evoking the strongest visual response were determined in this way with better than $5^{\circ}$ accuracy.

Mapping auditory responses in the deeper layers. Responses to auditory stimuli in the deeper layers of the SC tend to be a lot weaker and more variable than superficial-layer visual responses. They also have much larger receptive fields. In order to map auditory responses quantitatively, the amplified, extracellularly recorded signal was digitized at a rate of $24,000 \mathrm{~Hz}$, using a CED 1401plus interface. The digitized signal was then analyzed on a 80386 computer (Dell, Bracknell, UK) using our own spike sorting software, which grouped action potential shapes according to a number of features, including the amplitude of the first and second peaks and the duration of their various components. In this way it was possible to record simultaneously from two to six separate cells at any given recording position. The occurrence of spikes for each of the clusters was timed and stored on optical disk.

Twenty noise burst stimuli were presented at intervals of $1.3-1.5 \mathrm{sec}$ or greater (shorter interstimulus intervals tended to lead to a significant decline in response strength). The responses for each set of 20 presentations were recorded as raster plots and post stimulus time histograms (PSTH), and printed on line. As reported in a previous study using normal adult ferrets (King and Hutchings, 1987), acoustically responsive units typically displayed a response peak in the PSTH, usually starting within $10 \mathrm{msec}$ of stimulus onset, which was sometimes followed by a more sustained component. We also encountered a very small number of cells with inhibitory responses only, but these were not included in the quantitative analysis in this study. The duration of the response varied considerably from cell to cell and in many cases it was followed by a short period of reduced spontaneous activity. The 
A

Visual topography in study population

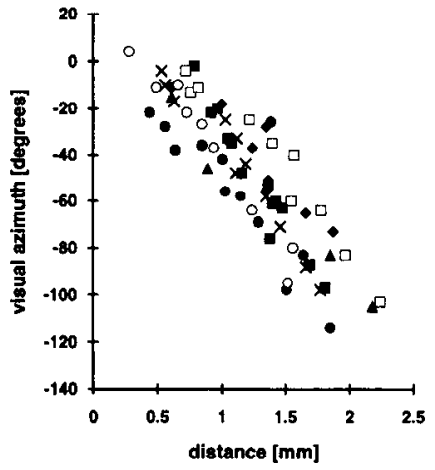

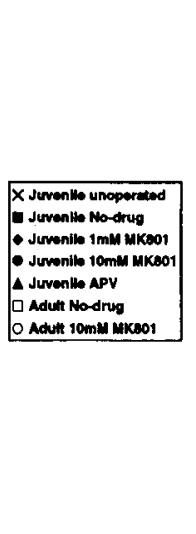

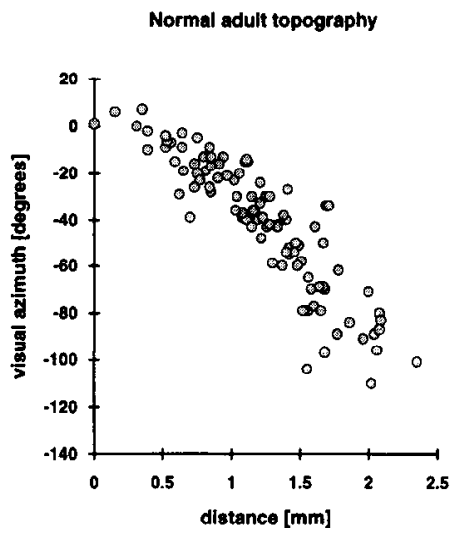

Figure 2. The representation of visual azimuth in the superficial layers of the superior colliculus in 16 of the animals used in this study $(A)$ and in 38 normal adult ferrets $(B)$. The best acinuths of multi-unit responses are plotted against the histological coordinates of the recording site between the rostral and caudal ends of the nucleus. $0^{\circ}$ lies directly in front of the animal and negative numbers denote positions contralateral to the recording site. The different symbols represent different experimental conditions, as indicated. The visual map was normal and adultlike in all conditions. amplitude and duration of the response varied with stimulus position and some units even switched from excitatory to inhibitory responses as the stimulus was moved away from the preferred position. Small changes in response latency with stimulus position were also observed.

Most units exhibited some degree of spontaneous firing, so the response peaks were superimposed on a baseline of spontaneous activity. We quantified the response strength by plotting an "aggregate PSTH" for each unit, pooling the data from all the recordings, binned with a 5 msec bin width. We then defined the "response window" for each unit as that part of the PSTH that included the excitatory peak, calculated the average number of spikes in that window per presentation, and subtracted from this the average number of spikes in an cquivalent length of time in the "spontaneous window" of the PSTH, to arrive at the number of evoked spikes. The spontaneous window was arbitrarily set as the period from 500 to $1000 \mathrm{msec}$ after stimulus presentation. Our recording software calculated this value on line and quantified the variability in the response strength between presentations by calculating its $95 \%$ confidence interval, a measure that we found helpful when trying to decide if a cell responded to sound at all, or when trying to establish its sensitivity threshold. Despite the changes in temporal firing pattern observed within the receptive field for some units, we found that varying the length of the response window usually had no effect on our estimates of spatial selectivity.

When an acoustically responsive unit was identified, its threshold was determined with the speaker located either at the center of the visual receptive field or, if different, at the auditory best position of other units in the same track. The threshold was sometimes redetermined if the preferred sound location of the new unit varied markedly from this region. The sound level was reduced until the number of evoked spikes was no longer significantly different from zero. Azimuthal response profiles were then obtained using noise stimuli at a sound level 25-30 $\mathrm{dB}$ above unit threshold. At this sound level relative to threshold both ears are stimulated at all stimulus locations and frequencies (Carlile, 1990).

In order to map the auditory receptive field of each unit, we determined the response strength at azimuthal locations that varied systematically in $20^{\circ}$ steps from $160^{\circ}$ contralateral to $160^{\circ}$ ipsilateral to the recording site, relative to the midline $\left(0^{\circ}\right)$. The elevation of the sound source was held constant at the best elevation of visual units recorded in the overlying superficial layers. Because the locations of both visual and auditory stimuli were defined in spherical coordinates, we used polar plots to visualize the azimuthal response profiles of the cells.

Reconstruction of recording sites. Once the recordings had been completed, the position of each electrode track was marked with one or two electrolytic lesions, by applying a negative current pulse of $5 \mu \mathrm{A}$ for 5 sec. At the end of the experiment the animal was perfused through the heart with $10 \%$ formaldehyde in physiological saline, the brain was blocked, removed, cryoprotected with $30 \%$ sucrose in formal saline, cut on a freezing microtome, and then Nissl stained for microscopic examination. Very little variation in the dimensions of the SC was observed in different animals. However, to obtain a measure of the location of each unit within the SC that is independent of individual size variation, the histological coordinates were expressed as a fraction of SC length and width and then plotted on a standardized SC template. All SC rostrocaudal coordinates refer to distances from the rostrolateral border on this standardized template, measured normal to the isoazimuth contours in normal, adult ferrets (King and Hutchings, 1987).

\section{Results}

Effects on the visual space map in the superficial layers

The chronic release of NMDA receptor blockers had little discernible effect on the visual responses in the superficial layers of the SC. As a rule we did not attempt to quantify responsiveness and receptive field dimensions with great accuracy, but, during our qualitative visual mapping procedures, we observed no obvious differences in response strength or size of the receptive fields between the different groups of animals or between any of these groups and normal adult ferrets.

The topography of the visual space map also appeared normal. Figure 2 shows the visual best positions for each recording site, plotted against their histological rostrocaudal coordinates, together with visual data from our normal, adult control population determined from previous studies (King and Hutchings, 1987; King and Carlile, 1993). For all conditions there was a very obvious negative regression of the azimuth of the visual best position on the histological position of the recording site, and the full extent of the visual field representation in each of the experimental conditions matched that of the normal adult ferrets.

The distribution of spatial selectivity among the animals recorded from in this study appeared to show very slightly more scalter and a sulall contralateral shift in the visual representation when compared to the normal adult data. However, these observations can be largely attributed to the different methods used to control eye position in the two populations. The data for the normal adult topography in Figure $2 B$ were obtained from pharmacologically paralyzed preparations, where variations in eye position were somewhat smaller than in the present study population, which were not paralyzed. We attempted to determine the eye position for each animal by backprojecting the optic disk position with an ophthalmoscope. In seven ferrets in which eye position was stabilized using conjunctival sutures, the mean $( \pm S D$ ) coordinates of the back-projected optic disk position were $-33( \pm 7)^{\circ}$ azimuth, $+13( \pm 7)^{\circ}$ elevation. In the paralyzed adult population $(N=38)$, the values were $-24( \pm 5)^{\circ}$ azimuth, $+11( \pm 6)^{\circ}$ elevation. The differences in mean azimuth and SD between the two populations are consistent with and probably fully explain the very small differences in the two topography plots of Figure 2. The underlying visual azimuth topographies therefore appeared to he equivalent in all our experimental conditions. 


\section{Auditory responses in the deeper layers}

Auditory responses were recorded in all four laminae that comprise the intermediate and deep layers of the SC. In order to determine whether the various treatments used in this study had any effect on the responsiveness of these neurons, we compared the maximal firing rate obtained for units in each group. A wide range of firing rates was found for all the conditions, but the mean values at the optimal loudspeaker position were very similar, varying between 1.4 and 1.8 spikes per stimulus presentation. These values, which are comparable to those reported for auditory units in normal, adult ferrets (King and Carlile, 1993) indicate that there were no differences in response strength between the animals treated with NMDA-receptor blockers and either the unoperated controls or those ferrets that received drugfree Elvax implants.

Most auditory units recorded in the deeper layers of the SC had a clear single peak in their azimuthal response profiles. Others showed two or more peaks, while the remainder had very broad response profiles with more or less uniform response strengths over an entire hemifield or more. We assessed the spatial tuning by dividing the responses into different categories. A peak in the response profile was defined as a region of activity of at least $80 \%$ of the maximal response, flanked by a reduction in activity to less than $40 \%$ on either side, and with the two low activity flanks not more than $160^{\circ}$ apart. Using this definition we classified the responses of the auditory cells into five groups: single-peaked cells, which we also refer to as "tuned" cells because they possess a clear single preferred stimulus position; "bilobed cells" (showing two peaks); "complex cells" (with three or more peaks); "broadly tuned cells" (showing an area of high response wider than $160^{\circ}$ at $40 \%$ of the maximum); and "omnidirectional cells" (lacking regions of space that evoke responses of less than 40\%). Reccptive field profiles were assigned to their respective classes according to these arbitrary but objective criteria by a computer, to prevent any observer bias.

Figure $3 A$ shows examples of the five types of response profile. The frequency with which these tuning categories were observed in each of the experimental conditions is shown in Figure $3 B$. Also included in this figure are data from normal, adult ferrets that were collected in earlier studies (King and Hutchings, 1987; King and Carlile, 1993; Carlile and King, 1994; King et al., 1994). The data for animals implanted with $1 \mathrm{mM}$ MK801 and $10 \mathrm{mM}$ MK801 at P25-27 have been pooled. This appeared to be justified because these two conditions did not differ significantly according to statistical measures of their auditory-visual misalignment (see below).

Higher proportions of tuned auditory units were found in the adult unoperated and drug-free Elvax control groups than in the corresponding juvenile ferrets. This is consistent with our previous findings that the incidence of bilobed responses decreases during the maturation of the space map as the proportion of tuned cells increases (King and Carlile, 1991; King, 1993). The relatively high proportion of nontuned cells in the juvenile control populations in this study therefore probably reflects their developmental immaturity. Consequently, we have restricted our comparison of data from animals subjected to chronic NMDA receptor blockade to the appropriate age-matched control groups.

All the experimental groups that were treated with NMDA receptor blockers, whether during the period of auditory space map development or in older animals, had a higher proportion

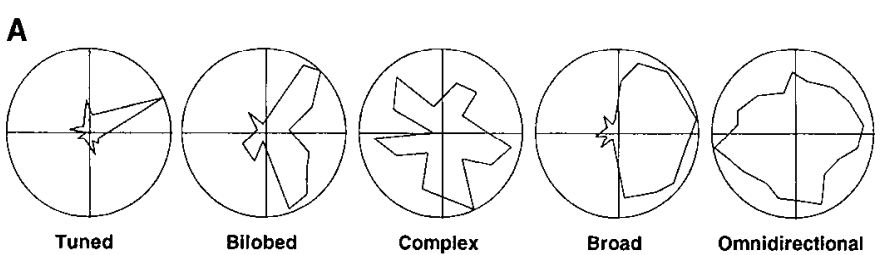

B

Proportions of receptive field types

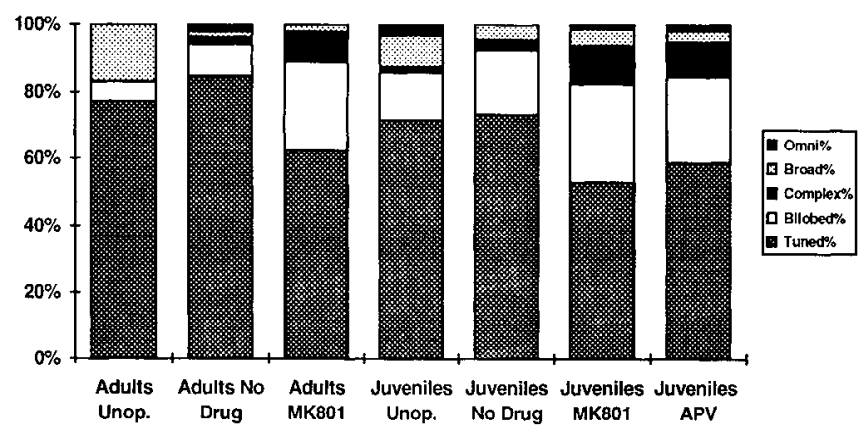

C

\section{Standard Error Estimates for Proportion of Tuned Cells}

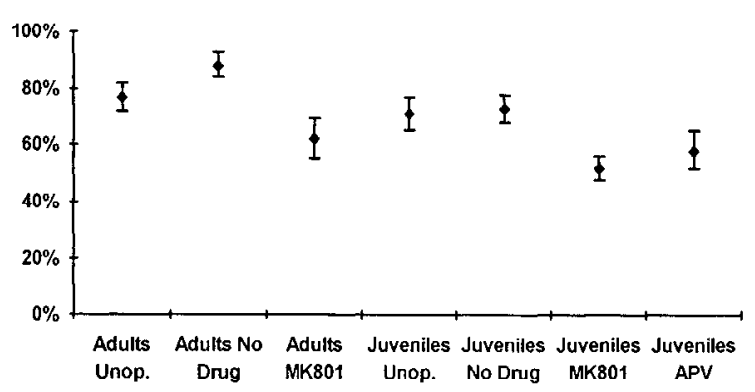

Figure 3. A, Normalized polar plots illustrating the five types of auditory azimuthal response profile observed in the deeper layers of the superior colliculus. In each case, the relative firing rate of the unit is plotted on the radial axis. Tuned cells respond maximally at a single azimuthal region. The response profiles of the other cell types indicate either ambiguous or poor spatial tuning. $B$, Histogram showing the relative proportions of each of the five receptive field types observed in unoperated normal adults (Adult Unop.) and in the six different experimental conditions used in this study. No drug designates drug-free Elvax controls. $C$, Mean and SE intervals for the proportion of tuned auditory units in each of the experimental groups.

of bilobed and complex cells and a lower proportion of tuned cells than the corresponding age-matched control groups. A $\chi^{2}$ test of proportions suggests that these differences are not just a sampling artefact $\left(p<0.001\right.$ for $\mathrm{H}_{0}=$ "proportion of tuned cells identical for all conditions"). SE estimates for the proportions of tuned cells can be derived from sampling theory, modeling the sampling of cells as a binomial process. These SEs arc shown in Figure $3 C$. They clearly suggest that at least some of the observed differences in receptive field types are genuine. By comparing the different experimental conditions individually (Bailey, 1981), we found that the proportion of tuned units in the juvenile animals treated with MK801 was significantly lower than in either the drug-free $(p<0.004)$ or unoperated juvenile controls $(p<0.008)$, although this was not the case with the ferrets reared with APV Elvax implants. The difference between the adult ferrets treated with MK801 and the adult drug-free (but not the normal adult) controls also reached significance $(p<$ 
0.006). Thus, chronic exposure of the SC to MK801 in both juvenile and adult ferrets leads to a reduction in the proportion of auditory units that are tuned to a single region in space.

\section{Effects on the auditory space map in the deep layers}

The observation that some auditory cells in all groups of animals did not display clear, unambiguous tuning to a single spatial position poses a problem when trying to describe the topography of the auditory representation. We have adopted two measures of spatial selectivity to assess the effects of NMDA-receptor blockers on the topography of this representation. For the analysis of tuned cells only, we used the position of the response peak as a measure of each cell's preferred direction or "best position" (King and Hutchings, 1987). The same measure was used to estimate auditory spatial selectivity in our earlier studies on the map of auditory space in the SC (e.g., King and Hutchings, 1987; King and Carlile, 1993; Carlile and King, 1994; King et al., 1994). A best position could, in principle, also be allocated to each of the peaks of the bilobed and complex response profiles. However, the number of best positions obtained depends on the arbitrary criteria used for defining a peak in the response profile. Moreover, this measure is not readily applied to the broadly tuned or omnidirectional units.

There is increasing evidence that stimulus location is encoded in the SC by the distribution of activity across a population of cells (Mcllwain, 1991). We have also calculated the "overall direction vector" for each auditory unit, which provides a measure of positional selectivity that reflects the mean contribution of each cell to the population response. A direction vector can be applied to all the cells regardless of the shape of their receptive field profiles. It is based on the vector sum of the response strengths for all the sampled stimulus positions, and, in Cartesian coordinates, is defined by

$$
x=\Sigma r \cos \phi \quad y=\Sigma r \sin \phi
$$

where $r$ is the response strength measured when the stimulus was presented from a direction given by $\phi$ (in degrees or radians azimuth). It follows that the direction of the overall direction vector $\theta$ is calculated by

$$
\Theta=\arctan (y / x) .
$$

A potential problem with vector sums as a measure of direction tuning is that they are sensitive to sampling bias. If twice as many points are sampled in a particular quadrant of the receptive field than in any other, the resultant vector may slant toward that quadrant, even if the strongest responses were observed in a different direction. We could not completely avoid sampling bias during the recording procedure because although we tried to space the recordings at regular intervals (typically $20^{\circ}$ steps), our hoop assembly did not allow the positioning of the speaker in a $30^{\circ}$ wide region of space behind the animal. Moreover, in some cases, individual recordings were repeated or particular regions of space were sampled in greater detail. Our algorithm therefore only ever added responses to the direction vector sum in groups of four orthogonal vectors, where missing data points were approximated by linear interpolation.

When calculating the direction vectors, the response strengths were expressed as a percentage of the maximum response for each cell, so that the length of the direction vector would serve as an index for the degree of tuning of each cell that is independent of its excitability. The lowest values for the mean length of the direction vectors were found in the ferrets that received
MK801-Elvax implants, which is consistent with the observed reduction in tuned units in these animals. The mean length of the direction vectors in the juvenile MK801 group was significantly lower than in the juvenile drug-free control group (Wilcoxon's rank-sum test; $z=3.82, p<0.001)$. However, the difference in mean length between the adult MK801 group and the adult drug-free controls just failed to reach significance $(z=$ $1.57, p>0.05)$.

The topography of the auditory representation based on both the best positions of tuned units only and the direction vector angles of all recorded auditory cells is shown for each experimental condition in Figures 4 and 5. Data from our earlier studies on the representation of auditory space in the SC of normal, adult ferrets have again been included as well (Figs. 4A, 5A).

The plots in Figure 4 illustrate the relation of auditory azimuth to distance of the recording site from the rostrolateral border of the SC. Comparison of Figure $4 A-C$ reveals a clear ncgative regression in the three groups of adult ferrets, indicating that the azimuthal selectivity of the units varied topographically within the SC. Despite the reduction in the proportion of tuned units following treatment with MK801 in adulthood, their auditory best positions extended over essentially the same range as in the two control groups. Moreover, the distribution of direction vector angles in the adult MK801 group, although slightly more scattered, was not significantly different from that in the drugfree animals (sce below for a detailed statistical treatment).

Compared to the corresponding adult groups, there is an increase in the scatter for the auditory topography plots in the juvenile unoperated controls (Fig. $4 D$ ) and the juvenile ferrets that received drug-free Elvax implants (Fig. $4 E$ ). As with the reduced proportion of tuned units, this is probably due to the developmental immaturity of the animals at the time of recording. The differences in scatter between these two juvenile control groups are not significant (see below) for either the best positions of tuned units or the direction vectors. It therefore appears that the experimental procedure of implanting the drug-free Elvax had no appreciable effect on the auditory map topography in either adult or juvenile ferrets.

The scatter in the auditory representation is appreciably larger in the ferrets reared with Elvax implants containing either MK801 (Fig. $4 F$ ) or APV (Fig. 4G) than in the age-matched control groups. Electrophysiological data were obtained from three APV-treated ferrets compared to seven animals that had been reared with MK801 implants. Consequently, fewer units were recorded in the APV group. Nevertheless, the increased scatter is still quite obvious. In particular, a relatively high proportion of points was found in the ipsilateral hemifield. This contrasts with the control groups where the representation was almost exclusively contralateral.

The panels in Figure 5 plot the auditory azimuthal coordinates of units recorded in the deeper layers against the visual best azimuth of superficial-layer units recorded in the same electrode penetration, and thus illustrate the degree of alignment between these representations. Because the topography of the visual map in the superficial layers was apparently normal in each experimental group (Fig. 2), these data essentially confirm the findings shown in Figure 4. Thus, the close correspondence between the visual and auditory maps found in normal, adult ferrets (Fig. $5 A$ ), was also evident in the adult ferrets that had received either drug-free (Fig. $5 B$ ) or MK801 Elvax implants (Fig. 5C). The correspondence between the visual and auditory representations was less precise in the juvenile unoperated (Fig. 5D) and drug- 


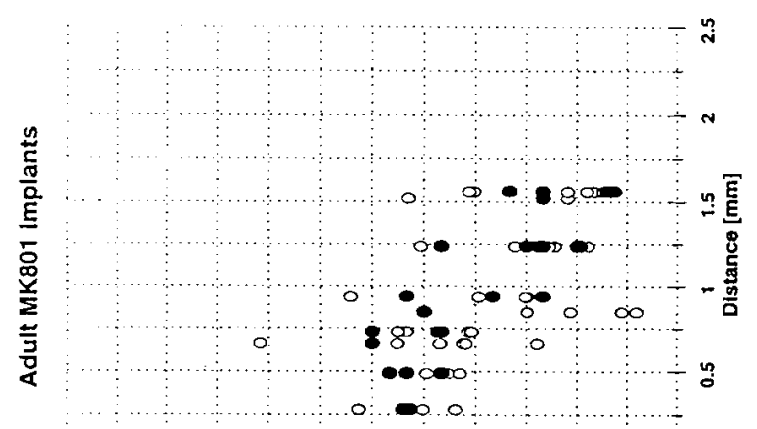

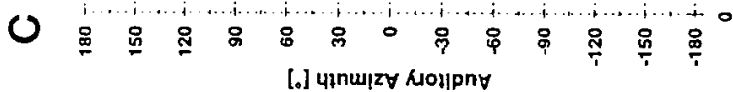

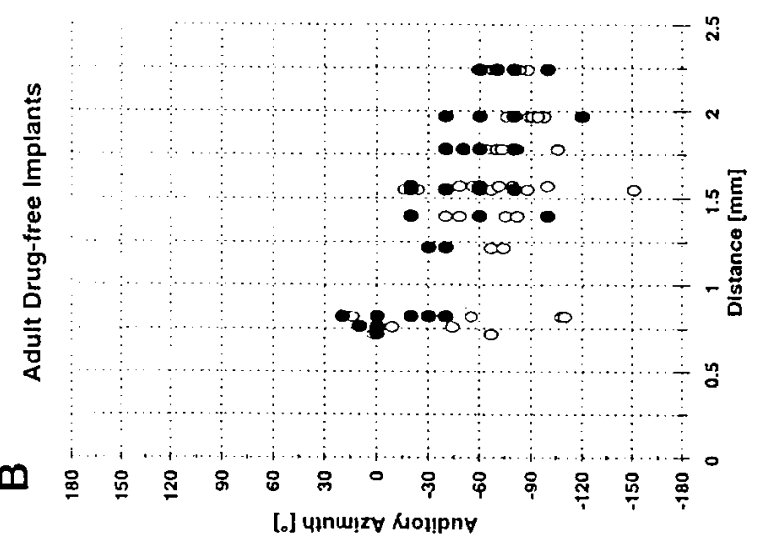

[.] uाnu!zళ Nou!pny

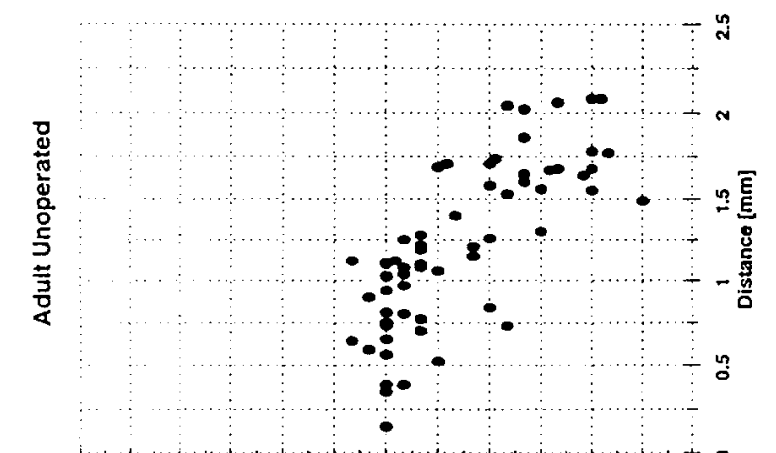

$<$ Ф

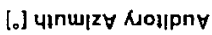

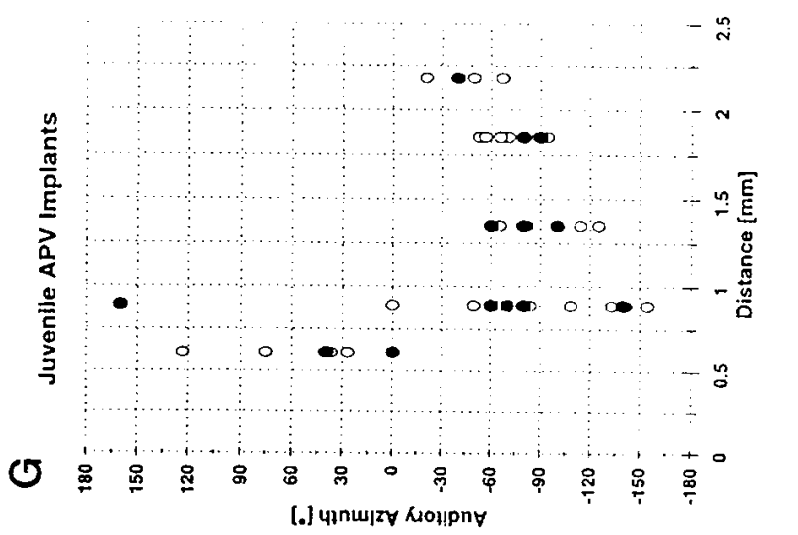

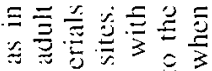

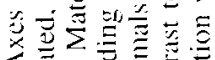

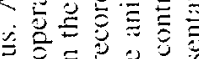

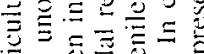

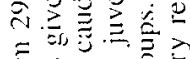

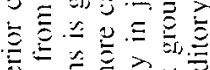

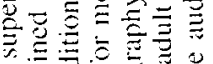

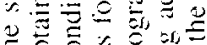

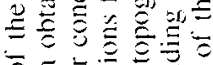

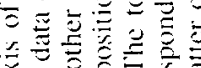

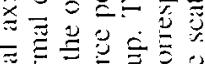

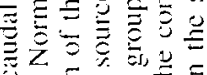

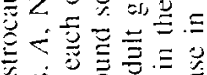

我田

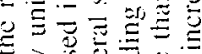

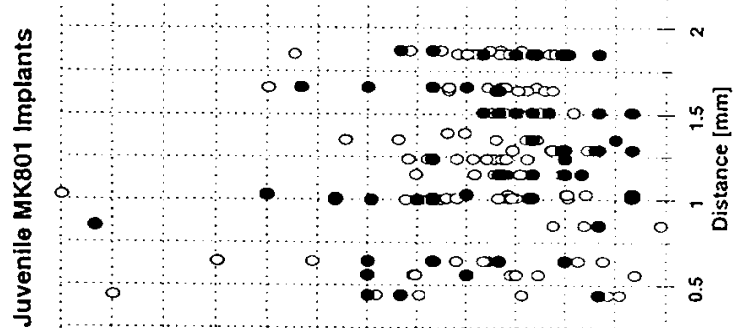

or,

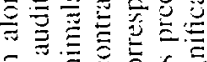

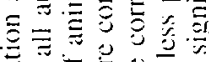

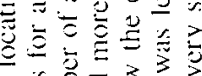

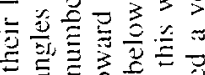

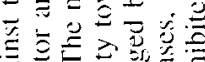

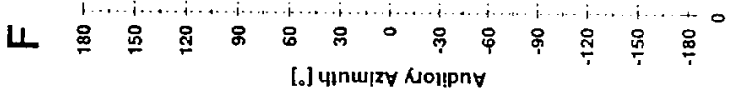

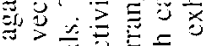

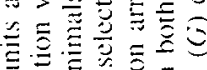

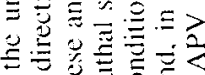

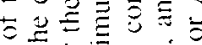

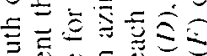

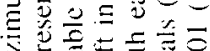

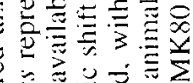

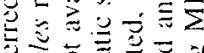

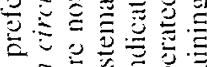

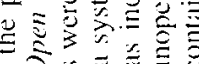

r.

$-0$

$\rightarrow 00 \quad 0 \vdots 000$

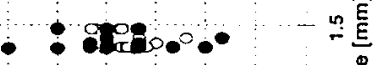

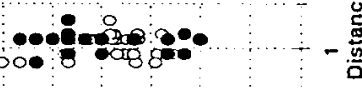

$\stackrel{n}{i}$

Ш

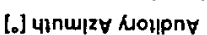

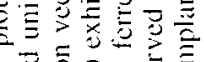

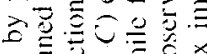

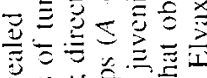

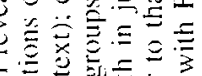

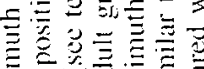

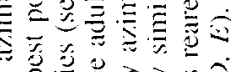

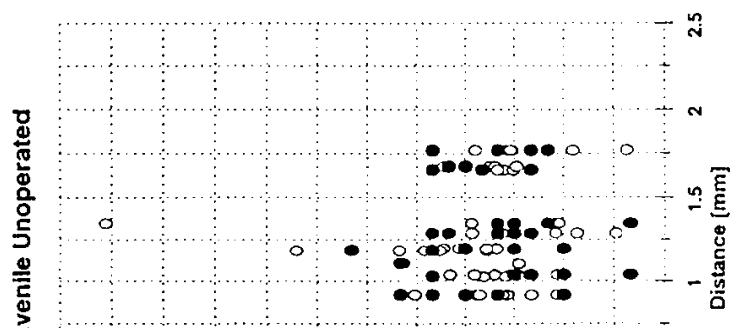

$-280$

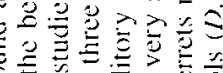

$\%$

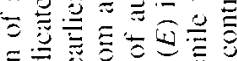

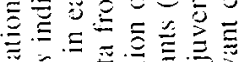

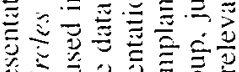

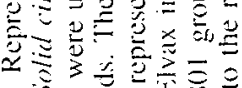

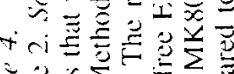

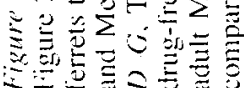



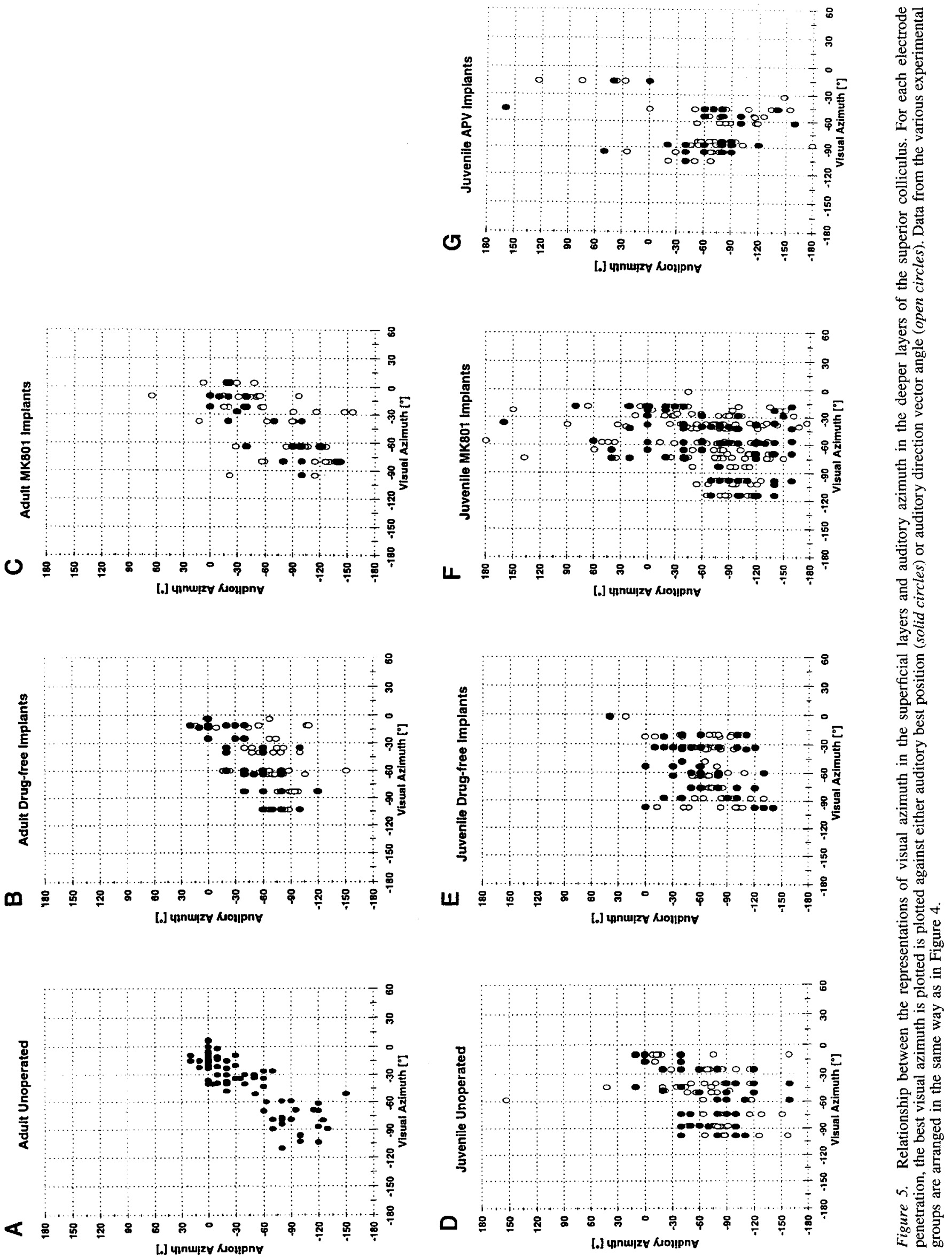

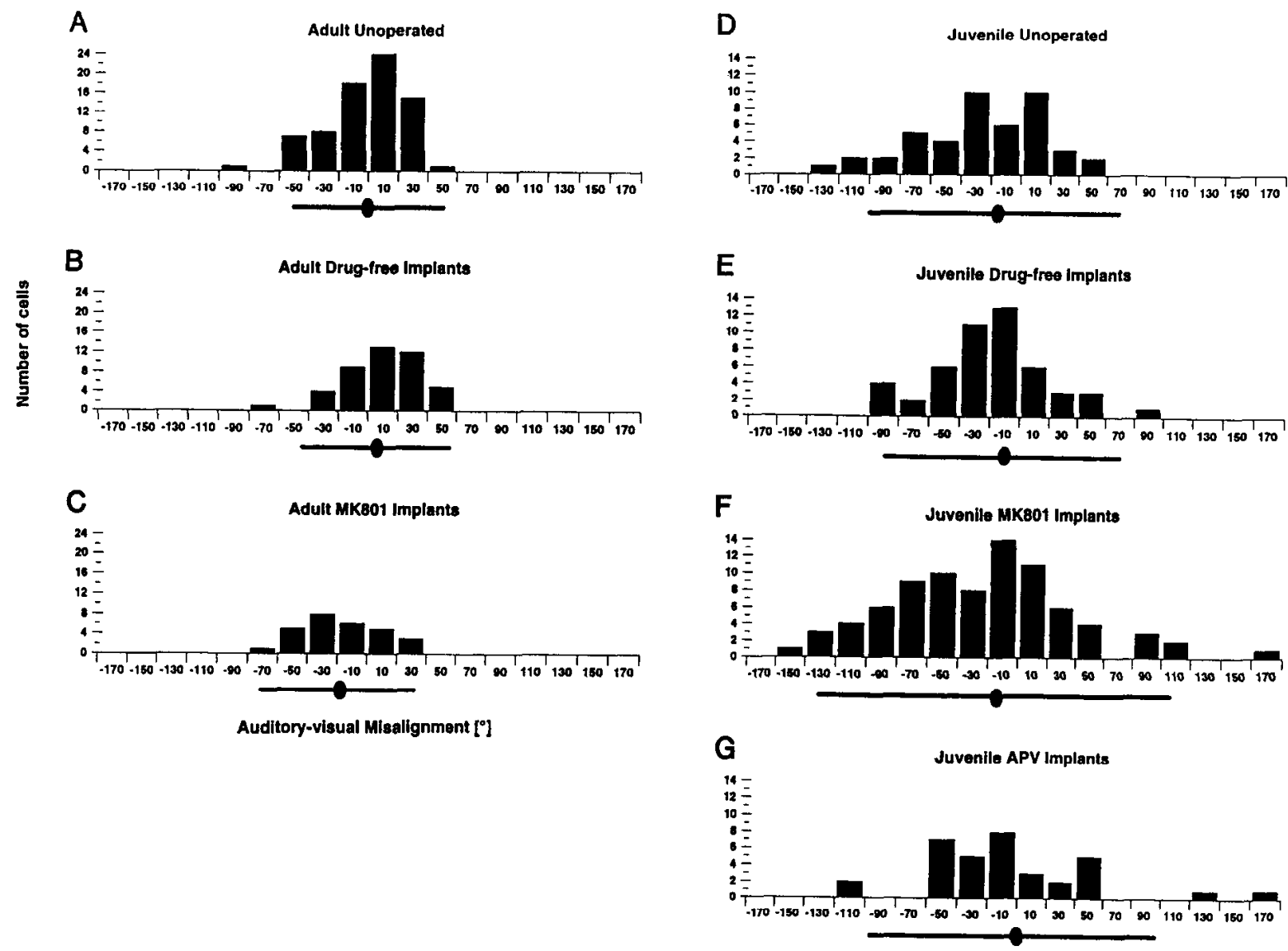

Auditory-visual Misallgnment [']

Figure 6. The effect of NMDA-receptor antagonists on auditory-visual misalignment in the superior colliculus. The histograms plot the angular difference hetween the azimuthal hest positions of visual units in the superficial layers and those of tuned auditory units recorded in the deeper layers of the same electrode penetration. The bar below each histogram is centered on the mean value and extends to two standard deviations on either side. The histograms are clearly widest in the conditions treated with MK801 and APV during development.

free control groups (Fig. 5E), indicating that the auditory representation was not fully mature at P61-70. However, much greater scatter in visual-auditory alignment was found in the juvenile animals that had been reared with either MK801 (Fig. $5 F$ ) or APV (Fig. $5 G$ ). Comparison of the auditory representation in adult (Figs. $4 C, 5 C$ ) and juvenile ferrets (Figs. $4 F, 5 F$ ) that had received MK801-Elvax implants for the same period of time strongly suggests a developmental effect of MK801 on the azimuthal selectivity of these units.

Since a normal bivariate distribution could not be assumed for these data, we did not use correlation coefficients to quantify the scatter in these topography plots (see Bailey, 1981). The most intuitive approach to a comparison of the topography and precision of the auditory representation among the different experimental groups would be to produce a descriptive function of the "juvenile topography" from our unoperated control data, and to use this as the basis for comparison with the data obtained in the other groups of juvenile animals. But, even though the total number of data points was quite large for this type of study, it was insufficient to find a function that accurately describes the unoperated control data. We would require either a larger sample or a good theoretical prediction how the data points spread around the presumed function describing the underlying juvenile topography. For example, we attempted to use a simple linear function to describe the relationship between the auditory and visual representations. However, the SE estimates for the slopes were so large that the regression lines were clearly unfit as a basis for comparison of topographies in the absence of any further constraining assumptions.

The relationship between the auditory spatial responses and either unit recording site or associated visual receptive field in juvenile ferrets gradually matures with increasing age toward the adult topography. We have therefore looked for order in the auditory data obtained in this study by quantifying how similar each group was to the (much more easily determined) topography of the representation in normal adults. One simple way of doing this, which has been used in other, related studies (e.g., Knudsen, 1985; Knudsen and Brainard, 1991) is to compare the observed differences between the auditory and visual coordinates of units recorded in the same vertical electrode track (auditory-visual misalignment). In normal adult ferrets the regression of auditory on visual a7imuth has a slope close to one and an intercept close to zero (see Fig. $5 A$ ), and the auditory-visual misalignments are small and approximately normally distributed.

We constructed auditory-visual misalignment histograms using both auditory best positions and direction vector angles for each of the experimental conditions. The histograms for the auditory best position data are shown in Figure 6. The narrowest histograms were found in the three groups of adult ferrets (Fig. $6 A-C)$, and the spread in misalignment values was very similar 
Table 1. Variance (scatter) in auditory-visual misalignments in adult study population

\begin{tabular}{|c|c|c|c|c|c|}
\hline \multirow[b]{2}{*}{ Condition } & \multirow[b]{2}{*}{$\begin{array}{l}\text { Method of } \\
\text { quantification }\end{array}$} & \multirow[b]{2}{*}{$\begin{array}{l}\text { Number } \\
\text { of units }\end{array}$} & \multirow[b]{2}{*}{$\begin{array}{l}\text { Variance of } \\
\text { misalignment }\end{array}$} & \multicolumn{2}{|c|}{$p$ Value of $F$ test comparing variance to: } \\
\hline & & & & Unoperated & $\begin{array}{l}\text { Drug-free } \\
\text { implants }\end{array}$ \\
\hline Unoperated & Best pos. tuned cells & 74 & 683 & - & \\
\hline Drug-free implants & Best pos. tuned cells & 44 & 606 & 0.74 & - \\
\hline Drug-free implants & Dir. vect. all cells & 52 & 1153 & - & - \\
\hline MK80I implants & Best pos. tuned cells & 28 & 704 & 0.48 & 0.84 \\
\hline MK801 implants & Dir. vect. all cells & 45 & 1745 & - & 0.18 \\
\hline
\end{tabular}

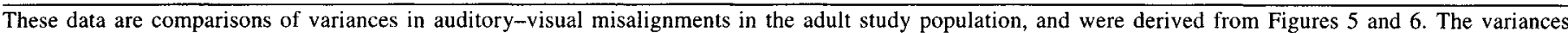

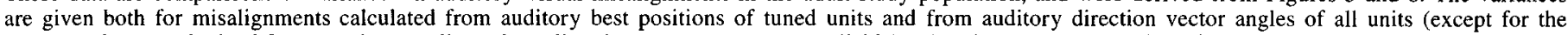

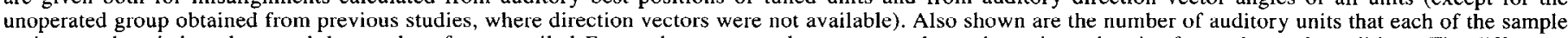

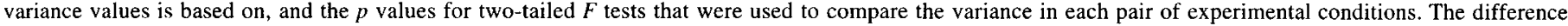
in variance failed to reach significance for any of the adult data sets shown here.

in each case. This again suggests the MK801 has no effect on the relationship between the visual and auditory representations in adult animals. Although wider histograms were obtained for the juvenile unoperated and drug-free control groups (Fig. $6 D, E$ ), the range of auditory-visual misalignments in the ferrets reared with MK801-Elvax implants (Fig. $6 F$ ) is clearly greater still, indicating an increased scatter in the auditory representation and therefore an age-dependent effect of this NMDA-receptor antagonist. The smaller number of data points for the juvenile APV condition resulted in a less impressive histogram (Fig. 6G), but if we use the variance of misalignments as a measure of the spread of the underlying distribution (see below), we find that this condition actually presents a very similar picture to that of the juvenile MK801 data.

Even though the misalignment histograms following developmental treatment with NMDA antagonists are significantly wider than those for the controls, their distribution is not as flat as one might expect if the auditory space map had been completely abolished. All the misalignment histograms in Figure 6 suggest unimodal distributions with clear peaks at low misalignment values, that is, the auditory best positions were still clustered, albcit with considerable spread in some cases, around the values found in the normal adult animals.

A similar picture was obtained when the same approach was applied to the direction vector data, which also include all the non-tuned auditory cells in the analysis. Again, the misalignment histogram for each experimental condition had a unimodal dis- tribution centered on small misalignment values. The variance of the misalignments was also greatest for the animals that had been treated with NMDA-receptor antagonists during development.

Having used $\chi^{2}$ goodness of fit tests to ascertain that none of these distributions varied significantly from a normal distribution, we applied an $F$ statistic to test whether the variance of misalignments (i.e., the width of the histograms) was significantly different between the different experimental conditions. An increase in the spread of the histograms (increased variance) indicates that the topographic arrangement of auditory best positions or direction vector angles across the SC deviates from normal and/or that the auditory representation is less precise, with a greater range of preferred azimuths at each recording site. Table 1 shows the variances of auditory-visual misalignments in adult ferrets, together with the $p$ values for two-tailed $F$ tests where $\mathrm{H}_{0}=$ "the two sample variances are equal." Table 2 provides equivalent values for the juvenile ferrets. Significant $p$ values are in bold print. Because of previously noted, age-related differences between the adult and juvenile control groups, we have treated the two age groups separately when applying this analysis. We have combincd the data from the juvenile ferrets that received Elvax implants containing $1 \mathrm{mM}$ MK801 and those in which the concentration of MK801 was $10 \mathrm{mM}$, as we found no significant difference in the variance of the auditory-visual misalignment between these two groups.

The data in Tables 1 and 2 confirm the observations based on

Table 2. Variance (scatter) in auditory-visual misalignments of the juvenile study population

\begin{tabular}{|c|c|c|c|c|c|c|}
\hline \multirow[b]{2}{*}{ Condition } & \multirow[b]{2}{*}{$\begin{array}{l}\text { Method of } \\
\text { quantification }\end{array}$} & \multirow[b]{2}{*}{$\begin{array}{l}\text { Number } \\
\text { of units }\end{array}$} & \multirow[b]{2}{*}{$\begin{array}{l}\text { Variance of } \\
\text { misalignment }\end{array}$} & \multicolumn{3}{|c|}{$p$ Value of $F$ test comparing variance to: } \\
\hline & & & & Unoperated & $\begin{array}{l}\text { Drug-free } \\
\text { implants }\end{array}$ & $\begin{array}{l}\text { MK801 } \\
\text { implants }\end{array}$ \\
\hline Unoperated & Best pos. tuned cells & 45 & 1765 & - & & \\
\hline Unoperated & Dir. vect. all cells & 63 & 2168 & - & & \\
\hline Drug-free implants & Best pos. tuned cells & 49 & 1573 & 0.79 & - & \\
\hline Drug-free implants & Dir. vect. all cells & 67 & 1134 & 0.07 & - & \\
\hline MK801 implants & Best pos. tuned cells & 84 & 3592 & 0.0117 & 0.0025 & - \\
\hline MK801 implants & Dir. vect. all cells & 159 & 3265 & 0.037 & 0.00004 & - \\
\hline APV implants & Best pos. tuned cells & 34 & 3434 & 0.0486 & 0.0162 & 0.9616 \\
\hline APV implants & Dir. vect. all cells & 58 & 3026 & 0.046 & 0.00015 & 1.713 \\
\hline
\end{tabular}

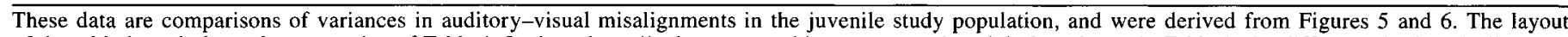

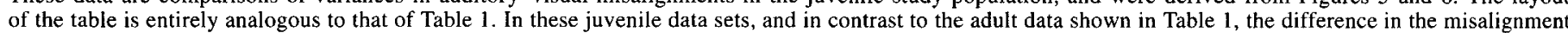

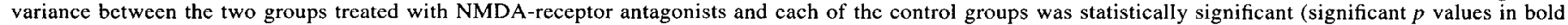
type). 

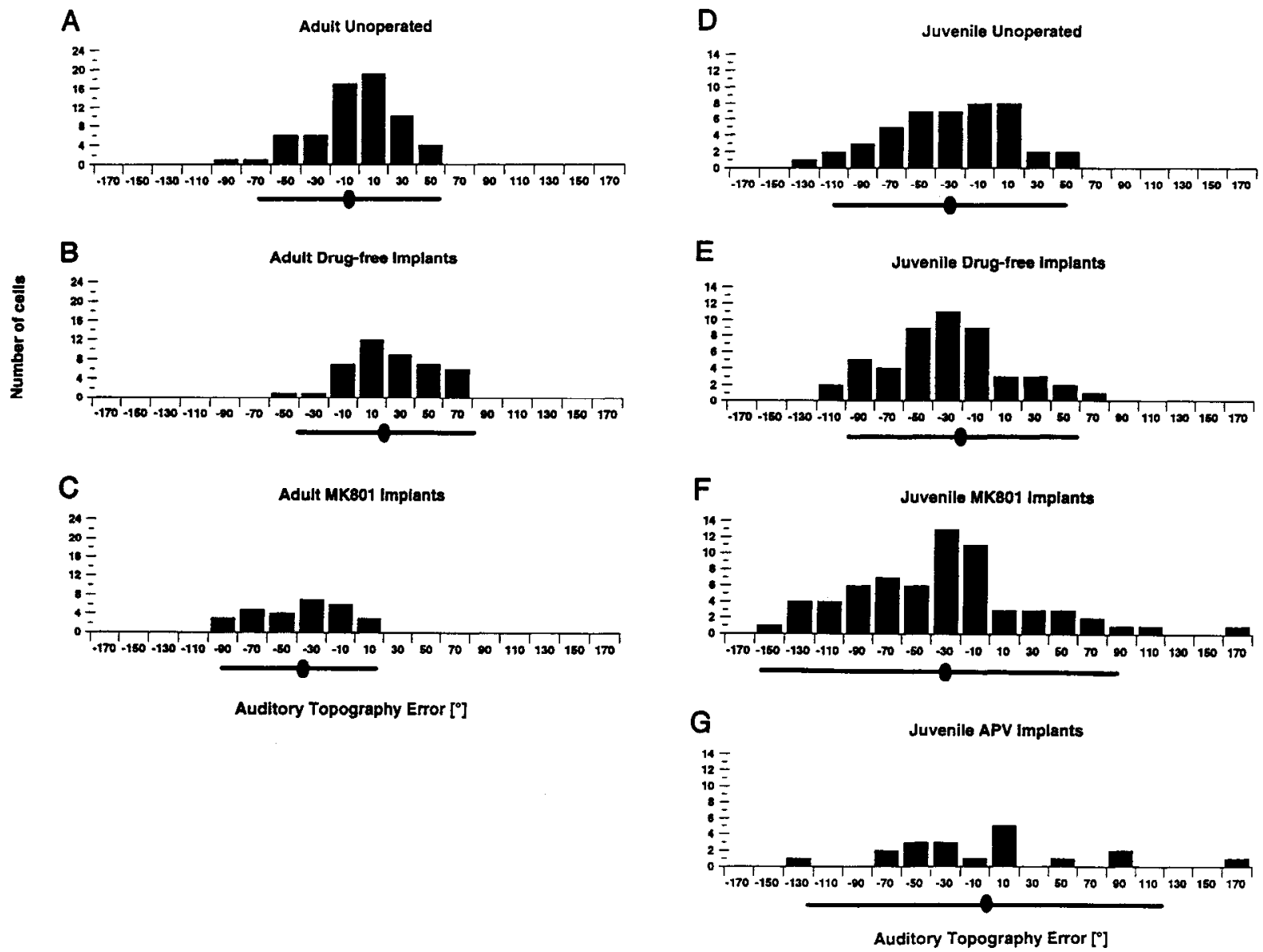

Figure 7. The effect of NMDA-receptor antagonists on the topography of the auditory representation. The histograms plot the angular difference between the azimuthal best positions of tuned auditory units recorded in the deeper layers of the superior colliculus and the expected value at each recording site, which was derived from the mathematical function that produced the best fit for the map of sound azimuth in normal adult ferrets (see Results). The bar below each histogram is centered on the mean value and extends to two SDs on either side. Data from the various experimental groups are arranged in the same way as in Figure 6. The histograms are again clearly widest in the conditions treated with MK801 and APV during development.

Figure 5, namely, that developmental NMDA receptor blockade leads to a significantly larger auditory-visual misalignment, but does not reduce the correspondence between the directional tuning of visual responses and that of auditory cells when applied at maturity. Considering the results of this analysis of auditoryvisual misalignments together with the observation that all animals possessed a normal visual topography (Fig. 2), it appears that features of a normal adult auditory topography were present under all conditions (the auditory azimuths cluster around a normal visual azimuth map), but that treatment with NMDA-receptor antagonists increases the scatter in the auditory representation significantly and in an age-dependent manner.

We also examined the auditory topography more directly by comparing the observed azimuthal selectivity with the values that would be predicted from the normal adult map for the anatomical location of the corresponding recording sites. In a previous study, King and Carlile (1993) found that the polynomial $Y=15.9-13 X-24.2 X^{2}$ produced the best fit for the auditory azimuth map in normal adult ferrets, with $X$ being the standardized electrode distance from the rostrolateral pole of the SC in $\mathrm{mm}$, and $Y$ the observed auditory best azimuth in degrees. With this formula we carried out an analysis of "auditory topography errors," using an entirely analogous approach to the analysis of misalignments, where the predicted auditory azimuths from the above equation were used instead of the visual azimuths.

The results of this analysis of topography errors entirely confirm the findings of the auditory-visual misalignment analysis. The histograms were again unimodal and centered on low error values (Fig. 7). Tables 3 and 4 give the variances in topography errors, for the analyses based on both best positions and direction vectors, as well as the $p$ values of the $F$ tests for the comparisons of these variances. The data in Table 3 are from the three adult groups, while those in Table 4 are derived from the four juvenile groups. These data again show that implanting drug-free Elvax onto the $\mathrm{SC}$ in either adult or juvenile ferrets has no effect on the auditory representation. Developmental NMDA-receptor blockade very significantly increases the scatter in the representation of sound azimuth, whereas the variance in adult animals is unaffected by this procedure. In each case, the same effect was found when the analysis was based on the best positions of the tuned units only and on the direction vectors of all recorded units.

\section{Depth effects}

The technique that we used required that the drug, once released from the Elvax, diffuses through the $\mathrm{SC}$ to reach its site of ac- 
Table 3. Variance (scatter) in auditory topography errors in adult study population

\begin{tabular}{|c|c|c|c|c|c|}
\hline \multirow[b]{2}{*}{ Condition } & \multirow[b]{2}{*}{$\begin{array}{l}\text { Method of } \\
\text { quantification }\end{array}$} & \multirow[b]{2}{*}{$\begin{array}{l}\text { Number } \\
\text { of units }\end{array}$} & \multirow{2}{*}{$\begin{array}{l}\text { Variance of } \\
\text { topography } \\
\text { error }\end{array}$} & \multicolumn{2}{|c|}{$p$ Value of $F$ test comparing variance to } \\
\hline & & & & Unoperated & $\begin{array}{l}\text { Drug-free } \\
\text { implants }\end{array}$ \\
\hline Unoperated & Best pos. tuned cells & 64 & 786 & - & \\
\hline Drug-free implants & Best pos. tuned cells & 43 & 882 & 0.13 & - \\
\hline Drug-free implants & Dir. vect. all cells & 52 & 1544 & - & - \\
\hline MK801 implants & Best pos. tuned cells & 28 & 808 & 0.65 & 0.93 \\
\hline MK801 implants & Dir. vect. all cells & 45 & 1692 & - & 0.85 \\
\hline
\end{tabular}

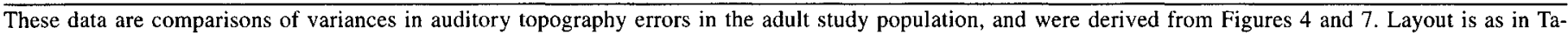
ble 1 .

tion. We might expect that concentration gradients would be established (see Fig. $1 B$ ), which, depending on the location of the NMDA receptors, would lead to a differential effect, with the most superficial units more seriously affected than deeper ones. To examine this possibility, we plotted the absolute auditory-visual misalignment for each unit against its depth, both for the juvenile drug-free controls and for the juvenile animals treated with MK801 (Fig. 8). A regression analysis suggested a lack of any significant relationship between depth and auditoryvisual misalignment, given that the slopes of the regression lines were close to and not significantly different from zero, and that the intercepts were close to the mean absolute misalignments for both conditions.

\section{Discussion}

NMDA receptors are thought to play an important role in the developmental plasticity of sensory systems (see reviews by Constantine-Paton et al., 1990; Rauschecker, 1991; Fox and Daw, 1993). Most of the evidence for this has come from studies demonstrating that plastic changes induced by altered sensory inputs to visual (Cline et al., 1987; Kleinschmidt et al., 1987; Scherer and Udin, 1989; Bcar ct al., 1990; Clinc and Constantine-Paton, 1990; Rauschecker et al., 1990), auditory (Brainard et al., 1992; Feldman and Knudsen, 1993), and somatosensory (Schlaggar et al., 1993) areas can be prevented by blocking NMDA receptors with appropriate antagonists. On the other hand, conflicting results have been obtained when similar approaches have been used to study the involvement of NMDA receptors in normal sensory development (Cline and Constantine-Paton, 1989; Hahm et al., 1991; Smetters et al., 1991; Simon et al., 1992; Schlaggar et al., 1993). In this study, we found that continuous treatment with the NMDA-receptor antagonists MK801 or APV for 5-6 weeks from P25-27 has no obvious effect on the topography of the visual space map in the superficial layers of the SC in ferrets. However, NMDA receptors do appear to play a role in establishing the preferred sound directions of auditory cells in the deeper layers. Treatment with MK801 or APV over this period disrupts the development of the map of sound azimuth, whereas chronic application of these drugs in older animals does not affect its topographic organization.

\section{The visual map}

Anatomical studies have suggested that NMDA receptors are involved in the refinement of the early retinocollicular projection. Thus, chronic NMDA-receptor blockade of the SC (or optic tectum) prevents both the elimination of inappropriately positioned terminal arbors in rats (Simon et al., 1992) and the maintenance of topographic order in developing retinal afferents in tadpoles (Cline and Constantine-Paton, 1989). Using the same methodology of implanting Elvax sheets containing MK801 or APV, we observed an apparently normal visual map, at least in terms of the receptive ficlds of multiunit responses, in the superficial layers of young ferrets. However, the visual projections in the ferret are largely mature at the age when the Elvax was introduced. Simon et al. (1992) implanted the Elvax on the SC in newborn rats when the retinocollicular projection is still disordered (Simon and O'Leary, 1992). In the ferret, the major changes in the organization of retinal projections are over well before P25, the age of the youngest animals used in this study. Ganglion cell death is complete by the end of the first postnatal week (Henderson et al., 1988; Cucchiaro, 1991; Thompson and

Table 4. Variance (scatter) in auditory topography errors of tuned cells in the juvenile study population

\begin{tabular}{|c|c|c|c|c|c|c|}
\hline \multirow[b]{2}{*}{ Condition } & \multirow[b]{2}{*}{$\begin{array}{l}\text { Method of } \\
\text { quantification }\end{array}$} & \multirow[b]{2}{*}{$\begin{array}{l}\text { Number } \\
\text { of units }\end{array}$} & \multirow{2}{*}{$\begin{array}{l}\text { Variance of } \\
\text { topography } \\
\text { error }\end{array}$} & \multicolumn{3}{|c|}{$p$ Value of $F$ test comparing variance to: } \\
\hline & & & & Unoperated & $\begin{array}{l}\text { Drug-free } \\
\text { implants }\end{array}$ & $\begin{array}{l}\text { MK801 } \\
\text { implants }\end{array}$ \\
\hline Unoperated & Best pos. tuned cells & 45 & 1697 & - & & \\
\hline Unoperated & Dir. vect. all cells & 63 & 1607 & - & & \\
\hline Drug-free implants & Best pos. tuned cells & 49 & 1567 & 0.894 & - & \\
\hline Drug-free implants & Dir. vect. all cells & 67 & 1064 & 0.102 & - & \\
\hline MK801 implants & Best pos. tuned cells & 66 & 3797 & 0.006 & 0.002 & - \\
\hline MK801 implants & Dir. vect. all cells & 122 & 3118 & 0.004 & 0.000004 & - \\
\hline APV implants & Best pos. tuned cells & 19 & 4382 & 0.015 & 0.007 & 0.913 \\
\hline APV implants & Dir. vect. all cells & 32 & 4680 & 0.0004 & 0.0000005 & 0.142 \\
\hline
\end{tabular}

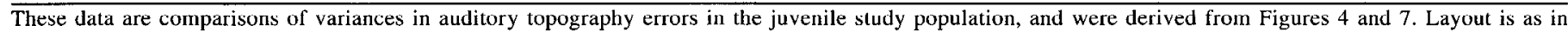
Table 2 . 
A

Juvenile drug-free implants

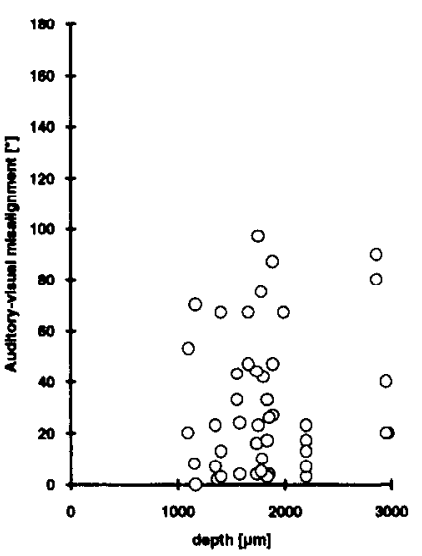

B

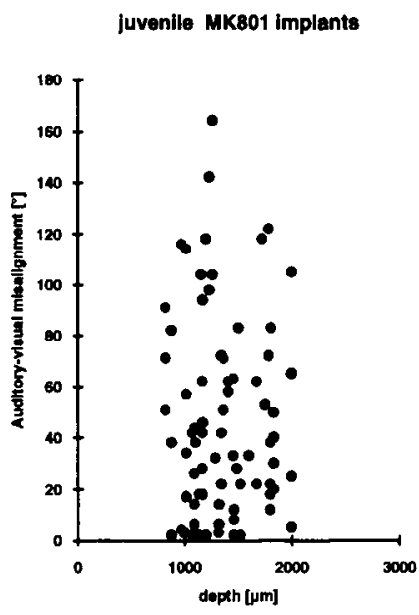

Figure 8. The auditory-visual misalignment is plotted against the depth of each auditory unit below the dorsal surface of the superior colliculus. $A$, Data from juvenile ferrets reared with drug-free Elvax. $B$, Data from juvenile ferrets reared with Elvax containing MK801. There is no obvious relationship between the distance of an auditory unit from the Elvax and the degree of correspondence in its spatial tuning with the visual map in either group.

Morgan, 1993), and the adult pattern of retinofugal terminations is established by P15 (Linden et al., 1981). Studies on the retinal projections to the thalamus and to the $\mathrm{SC}$ in newborn ferrets show that topographic order is present (Jeffrey, 1985; Snider and Chalupa, 1993; I. D. Thompson, P. Cordery, and A. J. King, unpublished observation), and that aberrant fibers have largely disappeared from the retinal terminal zones in the SC by P7 (Snider and Chalupa, 1993). It is therefore not surprising that adult-like topography can be demonstrated in the visual map in the superficial layers just after eye opening at approximately one. month after birth (King and Carlile, 1994).

NMDA receptors appear to play only a limited role in the synaptic transmission of visual information to the superficial layers of the SC in mammals (Roberts et al., 1991; Binns and Salt, 1994). This is consistent with our observation that the visual maps were normal, with respect to the strength of the responses as well as their topography. In the kitten SC, neurons in the deeper layers first begin to respond to visual stimuli after those in the superficial layers (Kao et al., 1991). We did not routinely examine the responses of deep-layer neurons to visual stimulation and therefore do not know whether their development is more susceptible to chronic NMDA-receptor blockade.

\section{The auditory map}

Auditory responses in the deeper layers of the SC in young ferrets (King and Carlile, 1991, 1994) and guinea pigs (Withington-Wray et al., 1990b) are initially very broadly tuned for sound location. In both cases, the topographic order in the auditory representation emerges several weeks after birth. The spatial selectivity of auditory neurons results from their tuning to acoustic cues generated by the head and outer ears. The principal cues used in the elaboration of the auditory map in the ferret $\mathrm{SC}$ are monaural pinna cucs and intcraural level differences (Carlile and King, 1994; King and Carlile, 1994; King et al., 1994). During the first month after the onset of hearing, which occurs at around P28 (Morey and Carlile, 1990), these cue val-

ues are continually changing as the head and pinnae continue to grow (Carlile, 1991; King and Carlile, 1994). The gradual emergence of the map of auditory space in the ferret SC follows a similar time scale, suggesting that the initial lack of order in this representation may, at least in part, reflect the immaturity of the acoustic cues available.

Nevertheless, there is considerable evidence that auditory and visual experience are utilized in shaping the spatial response properties of auditory neurons in the developing SC and in establishing the registration of this representation with the visual map (Knudsen, 1985; King et al., 1988; Withington-Wray et al., 1990a,c; Knudsen and Brainard, 1991; Knudsen et al., 1991; Mogdans and Knudsen, 1992; Withington, 1992; King and Carlile, 1993). Our findings suggest that the maturation of the auditory space map involves an activity-dependent process based on NMDA receptors. This is consistent with reports indicating a role for NMDA receptors in matching different maps in the amphibian (Scherer and Udin, 1989) and barn owl optic tectum (Brainard et al., 1992; Feldman and Knudsen, 1993) following manipulations of the sensory input.

As Fox and Daw (1993) have pointed out, a number of criteria need to be fulfilled before it can be concluded that NMDA receptors play a specific role in developmental plasticity. For example, the finding that NMDA-receptor blockade reduces not only the shift in ocular dominance following monocular deprivation (Kleinschmidt et al., 1987; Bear et al., 1990), but also the responsiveness of kitten cortical neurons to visual stimuli (Tsumoto et al., 1987; Fox et al., 1989), raises the possibility that these antagonists may simply attenuate the activity of the neurons below the threshold for adjusting to an altered visual input. We found that chronic treatment with MK801 or APV impaired the azimuthal preferences of many auditory units, but had no effect on the strength of their responses at the optimal speaker position. Our observation that the topographic order in the representation was disrupted following NMDA-receptor treatment from before the onset of hearing until just before the recordings were made, but not after a similar period of treatment in adult animals, suggests that these receptors do have a particular role in the development of the auditory space map.

Although MK801 and APV have both been reported to block certain non-NMDA receptors (e.g., Simon et al., 1992; Schlaggar et al., 1993), these drugs are thought to act primarily as selective NMDA-receptor antagonists (Davies et al., 1981; Wong et al., 1986; Monaghan et al., 1989). Moreover, the similarity in the results produced by MK801 and APV, which act at different sites on NMDA receptors, seems most likely to be due to a specific blockade of this class of glutamate receptor. Several studies have identified the presence of NMDA receptors in the superficial and deeper layers of the mammalian SC (Okada and Miyamoto, 1989; Moriyoshi et al., 1991; Roberts et al., 1991; Hestrin, 1992; Kao et al., 1993; Okada, 1993; Binns and Salt, 1994). The report by Hestrin (1992) that NMDA-receptor mediated synaptic currents in rat SC neurons are developmentally regulated is of particular interest in view of the age-related susceptibility of the auditory space map to NMDA-receptor blockade.

We do not know where the glutamatergic synapses involved in mediating the developmental plasticity of auditory neurons are located. Our in vivo measurements indicate that MK801 released from the Elvax penetrates at least as far as $800 \mu \mathrm{m}$ below the SC surface, although we saw no obvious variation in auditory spatial selectivity as a function of depth within the inter- 
mediate and deep layers following MK801 treatment in juvenile ferrets. The effective synapses could be located on dendrites close to the cell bodies from which we have recorded or nearer the surface of the SC on dendrites that extend up into the superficial layers (Mooney et al., 1984, 1992). That the distribution of NMDA receptors may differ across the SC laminae is suggested by the finding that the sensitivity of visual responses to iontophoretic application of APV varies with depth in adult cats (Binns and Salt, 1994).

Although our findings are most readily interpreted in terms of NMDA receptors located in the SC itself, we cannot rule out the possibility that MK801 and APV may have diffused from the Elvax to reach sources of auditory input to the SC. In barn owls, iontophoretic injection of APV into the external nucleus of the inferior colliculus (IC.) blocks the activity of cells in the optic tectum representing the same region of auditory space and, in particular, responses to new locations produced by rearing the animals with optically displaced visual fields (Feldman and Knudsen, 1993). The ferret SC receives bilateral, converging inputs from several auditory brainstem nuclei, with the largest projections originating from the brachium and the external nucleus of the ipsilateral IC (King et al., 1992). In view of the restricted area of the $\mathrm{SC}$ over which MK801 was released from the Elvax, we propose that the observed disruption of the normal development of the auditory space map is unlikely to be due to NMDA-receptor blockade at the sources of afferent input. Moreover, the highly signiticant difference between the auditory responses in the SC of ferrets reared with Elvax containing either MK801 or APV and of control animals that received drug-frec Elvax implants indicates that the observed disruption of the auditnry map cannot be attributed to the inclusion of ketamine, an NMDA-receptor blocker, in our anesthetic regime.

The presumptive role of NMDA receptors in other systems suggests that their activation may facilitate the detection of temporally correlated activity arising from visual and auditory stimuli located at the same region in space. As a consequence, auditory synapses could be stabilized during development when their activity is coordinated with that of converging visual afferents. This idea is supported by the finding that early displacement of visual receptive fields either by lateral deviation of the eye in ferrets (King et al., 1988) or by rearing barn owls with prismatic spectacles (Knudsen and Brainard, 1991) leads to a compensatory shift in the auditory representation. If NMDA receptors are involved in this process, we might expect that NMDA-receptor blockadc and deprivation of patterned visual cues would have similar consequences for the development of the auditory map. Both procedures lead to an increase in the proportion of auditory units that are ambiguously tuned to more than one location (compare Fig. 3 with King and Carlile, 1993). A crude auditory topography is still present in adult animals after binocular eyelid suture in infancy (Knudsen et al., 1991; Withington, 1992; King and Carlile, 1993). Similarly, NMDAreceptor blockade did not completely abolish the topography of the auditory representation because, although the azimuthal preferences of the auditory units were highly scattered, they were clustered around the positions that would be predicted from the normal adult map.

A topographically organized projection from the brachium of the ipsilateral IC along the rostrocaudal axis of the $\mathrm{SC}$ has been described in the adult ferret (Jiang et al., 1993), suggesting that the underlying order in the representation of sound azimuth may already be contained in the afferent input. The role of neural activity may therefore be to refine, rather than set up, the spatial preferences of the auditory responses of SC neurons during development. It is not presently known whether the sources of auditory input to the SC also undergo experience-dependent changes, although our preliminary observations suggest that the projection from the brachium of the ipsilateral IC contains a crude topographic order at birth (Z. D. Jiang, A. J. King, and I. D. Thompson, unpublished observation).

If synchronous visual activity is the only mechanism responsible for refining the spatial tuning of auditory cells in the deep layers of the $\mathrm{SC}$, then all tuned auditory cells in the SC should receive, at least in infancy, a significant visual input. Multimodal cells are widespread in the decper layers of the SC, and they tend to respond best to temporally matched and spatially coincident stimuli presented in combination (King and Palmer, 1985; Meredith and Stein, 1986a,b; Meredith et al., 1987). The proportion of neurons influenced by more than one modality is difficult to estimate because one sensory stimulus may modulate the response to another modality even though it appears to be ineffective by itself (King and Palmer, 1985). Studies in the cat have revealed that more than $50 \%$ of the auditory cells encountered were also visually responsive (Meredith and Stein, 1986a). This raises the question of whether this figure is higher earlier in development when our findings suggest that NMDA-receptor activity is involved in determining the preferred sound directions of the auditory neurons. However, Wallace et al. (1993) observed that multisensory neurons are rare in young kittens and that the proportion of such cells increases with age, reaching its maximum in adulthood. The majority of auditory neurons in normal, adult ferrets have single best positions that are arranged topographically within the SC, suggesting that, at some stage of their development, they are influenced by visual cues or that there are also vision-independent mechanisms for tuning their spatial responses. The latter possibility is supported by the finding that, in the absence of vision, occlusion of one ear leads to adaptive changes in the sensitivity to auditory localization cues of neurons in the developing barn owl optic tectum (Knudsen and Mogdans, 1992).

Besides correlating auditory and visual inputs to the $\mathrm{SC}$, NMDA receptors may play another role in the development of the auditory space map. We have previously shown that monaural pinna cues are responsible for auditory spatial selectivity at sound levels close to unit threshold (King et al., 1994), whereas both ILDs and spectral cues generated by the outer ears are utilized in maintaining the tuning with increasing sound level (Carlile and King, 1994; King et al., 1994). Following pinna removal in adult animals, the topography in the auditory representation is still apparent, although many of the suprathreshold azimuthal response profiles become bilobed, reflecting the spatial ambiguity in ILD cues (Carlile and King, 1994). On the other hand, if the same surgical procedure is performed in young ferrets, the auditory map fails to develop (King and Carlile, 1989). An activity-dependent process, possibly involving NMDA receptors, may therefore be involved in establishing the selectivity of SC cells for appropriate combinations of monaural and binaural localization cue values that correspond to a particular region of space.

\section{References}

Bailey NJT (1981) Statistical methods in biology. Cambridge: Cambridge UP.

Bear MF, Kleinschmidt A, Gu Q, Singer W (1990) Disruption of ex- 
perience-dependent synaptic modifications in striate cortex by infusion of an NMDA receptor antagonist. J Neurosci 10:909-925.

Binns KE, Salt TE (1994) Excitatory amino acid receptors participate in synaptic transmission of visual responses in the superficial layers of the cat superior colliculus. Eur J Neurosci 6:161-169.

Brainard MS, Feldman DE, Knudsen EI (1992) Learned auditory responses in the barn owl's optic tectum are preferentially suppressed by the NMDA receptor blocker ketamine. Soc Neurosci Abstr 18: 594.

Carlile S (1990) The auditory periphery of the ferret. I. Directional response properties and the pattern of interaural level differences. $J$ Acoust Soc Am 88:2180-2195.

Carlile S (1991) The auditory periphery of the ferret: postnatal development of acoustic properties. Hearing Res 51:265-278.

Carlile S, Hollingshead E (1991) ALDISS: a digital sound generating system using a $386 \mathrm{PC}$ and a fast DA converter. Br J Audiol 26:191.

Carlile S, King AJ (1994) Monaural and binaural spectrum level cues in the ferret: acoustics and the neural representation of auditory space. J Neurophysiol 71:785-801.

Cline HT, Constantine-Paton M (1989) NMDA receptor antagonists disrupt the retinotectal topographic map. Neuron 3:413-426.

Cline HT, Constantine-Paton M (1990) NMDA receptor agonist and antagonists alter retinal ganglion cell arbor structure in the developing frog retinotectal projection. J Neurosci 10:1197-1216.

Cline HT, Debski EA, Constantine-Paton M (1987) N-Methyl-D-aspartate receptor antagonist desegregates eye-specific stripes. Proc Natl Acad Sci USA 84:4342-4345.

Constantine-Paton M, Cline HT, Debski E (1990) Patterned activity, synaptic convergence, and the NMDA receptor in developing visual pathways. Annu Rev Neurosci 13:129-154.

Cucchiaro JB (1991) Early development of the retinal line of decussation in normal and albino ferrets. J Comp Neurol 312:193-206.

Davies JD, Francis AA, Jones AW, Watkins JC (1981) 2-Amino-5phosphonovalerate (2APV), a potent and selective antagonist of amino acid-induced and synaptic excitation. Neurosci Letl 21:77-81.

Feldman DE, Knudsen EI (1993) Newly learned auditory responses in barn owl optic tectum are preferentially blocked by APV applied in the ICx. Soc Neurosci Abstr 19:888.

Fox K, Daw NW (1993) Do NMDA receptors have a critical function in visual cortical plasticity? Trends Neurosci 16:116-122.

Fox K, Sato H, Daw N (1989) The location and function of NMDA receptors in cat and kitten visual cortex. $\mathbf{J}$ Neurosci 9:2443-2454.

Hahm J-O, Langdon RB, Sur M (1991) Disruption of retinogeniculate afferent segregation by antagonists to NMDA receptors. Nature 351: $568-570$.

Henderson Z, Finlay BL, Wikler KC (1988) Development of ganglion cell topography in ferret retina. $J$ Neurosci 8:1194-1205.

Hestrin S (1992) Developmental regulation of NMDA receptor-mediated synaptic currents at a central synapse. Nature 357:686-689.

Jeffery G (1985) Retinotopic order appears before ocular separation in developing visual pathways. Nature 313:575-576.

Jiang ZD, King AJ, Moore DR (1993) Topographic projection from the brachium of the inferior colliculus to the space-mapped region of the superior colliculus in the ferret. Br J Audiol 27:344 345.

Kao C-Q, McHaffie JG, Meredith MA, Stein BE (1991) Physiological maturation of the visual topography in the cat superior colliculus. Soc Neurosci Abstr 17:1378.

Kao C-Q, Stein BE, Coulter DA (1993) Postnatal development of synaptic responses in deep layers of superior colliculus slices studied using whole cell patch techniques. Soc Neurosci Abstr 19:768

King AJ (1993) A map of auditory space in the mammalian brain: neural computation and development. Exp Physiol 78:559--590.

King AJ, Carlile S (1989) Generation of an auditory space map in the ferret superior colliculus requires the presence of monaural localization cues. Soc Neurosci $\Lambda$ bstr 15:746.

King AJ, Carlile S (1991) Maturation of the map of auditory space in the superior colliculus of the ferret. Soc Neurosci Abstr 17:231.

King AJ, Carlile S (1993) Changes induced in the representation of auditory space in the superior colliculus by rearing ferrets with binocular eyelid suture. Exp Brain Res 94:444-455.

King AJ, Carlile S (1994) Neural coding for auditory space. In: The cognitive neurosciences (Gazzaniga MS, ed), pp 279-293. Cambridge, MA: MIT Press.

King AJ, Hutchings ME (1987) Spatial response properties of acous- tically responsive neurons in the superior colliculus of the ferret: a map of auditory space. J Neurophysiol 57:596-624.

King AJ, Palmer AR (1985) Integration of visual and auditory information in bimodal neurones in the guinea-pig superior colliculus. Exp Brain Res 60:492-500.

King AJ, Hutchings ME, Moore DR, Blakemore C (1988) Developmental plasticity in the visual and auditory representations in the mammalian superior colliculus. Nature 332:73-76.

King AJ, Jiang ZD, Moore DR (1992) Auditory brainstem projections to the superior colliculus of the ferret. Soc Neurosci Abstr 18:843.

King AJ, Moore DR, Hutchings ME (1994) Topographic representation of auditory space in the superior colliculus of adult ferrets after monaural deafening in infancy. $J$ Neurophysiol 71:182-194.

Kleinschmidt A, Bear MF, Singer W (1987) Blockade of "NMDA" receptors disrupts experience-dependent plasticity of kitten striate cortex. Science 238:355-358.

Knudsen EI (1985) Experience alters the spatial tuning of auditory units in the optic tectum during a sensitive period in the barn owl. J Neurosci 5:3094-3109.

Knudsen EI (1991) Dynamic space codes in the superior colliculus. Curr Opinion Neurobiol 1:628-632.

Knudsen EI, Brainard MS (1991) Visual instruction of the neural map of auditory space in the developing optic tectum. Science 253:8587.

Knudsen EI, Mogdans J (1992) Vision-independent adjustment of unit tuning to sound localization cues in response to monaural occlusion in developing owl optic tectum. J Neurosci 12:3485-3493.

Knudsen EI, Esterly SD, du Lac S (1991) Stretched upside-down maps of auditory space in the optic tectum of blind-reared owls; acoustic basis and behavioral correlates. J Neurosci 11:1727-1747.

Linden DC, Guillery RW, Cucchiaro J (1981) The dorsal lateral geniculate nucleus of the normal ferret and its postnatal development. J Comp Neurol 203:189-211.

Mcllwain JT (1991) Distributed spatial coding in the superior colliculus: a review. Vis Neurosci 6:3-13.

Meredith MA, Stein BE (1986a) Visual, auditory, and somatosensory convergence on cells in superior colliculus results in multisensory integration. J Neurophysiol 56:640-662.

Meredith MA, Stein BE (1986b) Spatial factors determine the activity of multisensory neurons in cat superior colliculus. Brain Res 365: 350-354

Meredith MA, Nemitz JW, Stein BE (1987) Determinants of multisensory integration in the superior colliculus I. temporal factors. J Neurosci 7:3215-3229

Mogdans J, Knudsen EI (1992) Adaptive adjustment of unit tuning to sound localization cues in response to monaural occlusion in developing owl optic tectum. J Neurosci 12:3473-3484.

Monaghan DT, Bridges RJ, Cotman CW (1989) The excitatory amino acid receptors: their classes, pharmacology, and distinct properties in the function of the central nervous system. Annu Rev Pharmacol Toxicol 29:365-402.

Mooney RD, Bradley GK, Jacquin MF, Rhoades RW (1984) Dendrites of deep layer, somatosensory superior colliculus neurons extend into the superficial laminae. Brain Res 324:361-365.

Mooney RD, Huang X, Rhoades RW (1992) Functional influence of interlaminar connections in the hamster's superior colliculus. J Neurosci $12: 2417-2432$.

Morey AL, Carlile S (1990) Auditory brainstem of the ferret: maturation of the brainstem auditory evoked response. Dev Brain Res 52: $279-288$.

Moriyoshi K, Masu M, Ishii T, Shigemoto R, Mizuno N, Nakanishi S (1991) Molecular cloning and characterization of the rat NMDA receptor. Nature 354:31-37.

Okada Y (1993) The properties of the long-term potentiation (LTP) in the superior colliculus. Prog Brain Res 95:287-296.

Okada Y, Miyamoto T (1989) Formation of long-term potentiation in superior colliculus slices from the guinea pig. Neurosci Lett 96:108113.

Rauschecker JP (1991) Mechanisms of visual plasticity: Hebb synapses, NMDA receptors, and beyond. Physiol Rev 71:587-615.

Rauschecker JP, Egert U, Kossel A (1990) Effects of NMDA antagonists on developmental plasticity in kitten visual cortex. Int J Dev Neurosci 8:425-435.

Roberts WA, Eaton SA, Salt TE (1991) Excitatory amino acid recep- 
tors mediate synaptic responses to visual stimuli in superior colliculus neurones of the rat. Neurosci Lett 129:161-164.

Scherer WJ, Udin SB (1989) $N$-Methyl-D-aspartate antagonists prevent interaction of binocular maps in Xenopus tectum. J Neurosci 9:38373843.

Schlaggar BL, Fox K, O'Leary DDM (1993) Postsynaptic control of plasticity in developing somatosensory cortex. Nature 364:623-626.

Schnupp WJH, King AJ, Smith AL, Thompson ID (1993a) The NMDA receptor antagonist MK-801 disrupts the development of the auditory space map in the superior colliculus. Soc Neurosci Abstr 19:887.

Schnupp WJH, King AJ, Smith AL, Thompson ID (1993b) Influence of chronic exposure to NMDA-receptor antagonists on the development of auditory responses in the ferret superior colliculus. $\mathrm{Br} \mathrm{J} \mathrm{Au}-$ diol 27:345-346.

Simon DK, O'Leary DDM (1992) Development of topographic order in the mammalian retinocollicular projection. J Neurosci 12:12121232.

Simon DK, Prusky GT, O'Leary DDM, Constantine-Paton M (1992) $N$-methyl-D-aspartate receptor antagonists disrupt the formation of a mammalian neural map. Proc Natl Acad Sci USA 89:10593-10597.

Smetters DK, Hahm J, Sur M (1991) An NMDA antagonist does not disrupt normal eye-specific laminar segregation of ferret retinogeniculate axons. Soc Neurosci Abstr 17:1136.

Snider CJ, Chalupa LM (1993) Specificity of the retinocollicular pathway in developing cat and ferret. Soc Neurosci Abstr 19:454.

Stein BE, Meredith MA (1993) The merging of the senses. Cambridge, MA: MIT Press.
Thompson ID, Morgan JE (1993) The development of retinal ganglion cell decussation patterns in postnatal pigmented and albino ferrets. Eur J Neurosci 5:341-356.

Tsumoto T, Hagihara K, Sato H, Hata Y (1987) NMDA receptors in the visual cortex of young kittens are more effective than those of adult cats. Nature 327:513-514.

Wallace MT, Meredith MA, Stein BE (1993) Development of multisensory integration in cat superior colliculus. Soc Neurosci Abstr 19: 240

Withington DJ (1992) The effect of binocular eyelid suture on auditory responses in the guinea-pig superior colliculus. Neurosci Lett 136: 153-156.

Withington-Wray DJ, Binns KE, Kcating MJ (1990a) The maturation of the superior collicular map of auditory space in the guinea pig is disrupted by developmental visual deprivation. Eur J Neurosci 2:682692.

Withington-Wray DJ, Binns KE, Keating MJ (1990b) The developmental emergence of a map of auditory space in the superior colliculus of the guinea pig. Dev Brain Res 51:225-236.

Withington-Wray DJ, Binns KE, Dhanjal SS, Brickley SG, Keating MJ (1990c) The maturation of the superior collicular map of auditory space in the guinea pig is disrupted by developmental auditory deprivation. Eur J Neurosci 2:693-703.

Wong EIII, Kemp JA, Priestly T, Knight AR, Woodruff GN, Iversen LL (1986) The anticonvulsant MK-801 is a potent $N$-methyl-D-aspartate antagonist. Proc Natl Acad Sci USA 83:7104-7108. 